\title{
Protection of Data Processing Equipment with Fine Water Sprays
}

William Grosshandler

Darren Lowe

Kathy Notarianni

William Rinkinen

Building and Fire Research Laboratory

Gaithersburg, Maryland 20899
Sponsored by:

Federal Emergency Management Agency

United States Fire Administration

16825 S. Seton Avenue

Emmitsburg, Maryland 21721

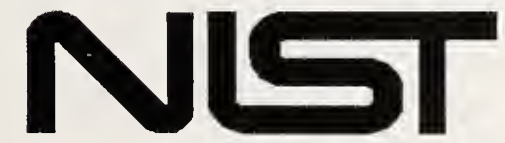

United States Department of Commerce

Technology Administration

QC Vational Institute of Standards and Technology

100

.056

N0. 5514 



\section{Protection of Data Processing Equipment with Fine Water Sprays}

William Grosshandler

Darren Lowe

Kathy Notarianni

William Rinkinen

October 1994

Building and Fire Research Laboratory

National Institute of Standards and Technology

Gaithersburg, MD 20899

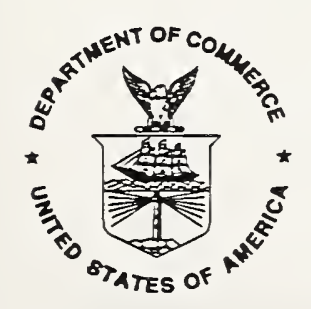

\section{U.S. Department of Commerce}

Ronald H. Brown, Secretary

Technology Administration

Mary L. Good, Under Secretary for Technology

National Institute of Standards and Technology

Arati Prabhakar, Director 



\section{TABLE OF CONTENTS}

page

ACKNOWLEDGEMENT

$\mathrm{v}$

ABSTRACT

vii

1. Background

1.1 Fine Water Sprays Compared to Sprinklers and Halon Systems

1.2 Fire Protection Needs for Data Processing Equipment 3

1.3 Research Objective and General Approach 3

2. Experimental Facility $\quad 5$

2.1 Generic Electronics Cabinet 5

2.2 Spray Chamber $\quad 8$

2.3 Instrumentation $\quad 8$

$\begin{array}{ll}\text { 2.3.1 Flow and pressure measurements } & 8\end{array}$

$\begin{array}{ll}\text { 2.3.2 Droplet size and velocity } & 13\end{array}$

2.4 Operating Procedures and Data Acquisition 20

$\begin{array}{ll}\text { 2.4.1 Unobstructed fire tests } & 20\end{array}$

$\begin{array}{ll}\text { 2.4.2 Generic electronics cabinet tests } & 20\end{array}$

2.4.3 Phase Doppler particle analyzer $\quad 22$

$\begin{array}{ll}\text { 2.4.4 Data acquisition system } & 22\end{array}$

3. Experimental Results $\quad 24$

$\begin{array}{lll}3.1 & \text { Test Matrix } & 24\end{array}$ 
3.2 Flow Characteristics with No Test Article Present 26

$\begin{array}{lll}3.2 .1 & \text { Pressure-jet nozzle } & 26\end{array}$

$\begin{array}{ll}3.2 .2 & \text { Air-atomized nozzle }\end{array}$

$\begin{array}{ll}\text { 3.2.3 Gaseous agent nozzle } & 26\end{array}$

$\begin{array}{ll}3.3 \text { Unobstructed Fire Experiments } & 28\end{array}$

3.4 Enclosed Fires 29

$\begin{array}{ll}\text { 3.4.1 Experimental matrix } & 29\end{array}$

$\begin{array}{ll}\text { 3.4.2 Water spray results } & 29\end{array}$

$\begin{array}{ll}\text { 3.4.3 Suppression with gaseous } \mathrm{CF}_{3} \mathrm{H} & 47\end{array}$

4. Conclusions and Recommendations $\quad 50$

5. References $\quad 52$ 


\section{ACKNOWLEDGEMENT}

This work has been sponsored by the Federal Emergency Management Agency, United States Fire Administration. We wish to acknowledge the helpful guidance provided by Mr. Larry Maruskin of the Fire Administration. Useful discussions, and, in some cases, prototypical hardware were provided by the following nongovernmental organizations: Securiplex, Reliable Sprinkler, Spraying Systems Inc., Marioff Hi-fog, NFPA Water Mist Committee, Hughes Associates, Factory Mutual, and IBM. The technical assistance of Aerometrics in support of the phase-Doppler particle analyzer is also acknowledged. 


\begin{abstract}
The major objective of the work presented here has been to determine how a fine water spray compares to a gaseous agent in extinguishing fires in data processing equipment, an environment typically protected by halon 1301. A scaled-down, generic electronics package was designed and a chamber built to contain the water spray to emulate the physical system of interest. The mock electronics cabinet is $0.5 \mathrm{~m}$ wide, $0.2 \mathrm{~m}$ deep and $0.4 \mathrm{~m}$ high. The fuel is a $3 \mathrm{~mm}$ thick plate of poly(methyl methacrylate), placed vertically in an aluminum frame centered among a number of aluminum "circuit boards." The limitations imposed by the different transport phenomena associated with droplet versus gas dispersion have been investigated. The influence on extinguishing efficiency of the nozzle geometry, the location relative to the fire, the water application rate, and the amount of shielding surrounding the fire within the simulated cabinet are all parameters which have been examined. A gaseous agent, $\mathrm{CF}_{3} \mathrm{H}$, is used for comparison. A phase-Doppler particle analyzer measured the droplet size distribution and velocity. The water pressure has a significant effect on the size of the region in which a fire can be effectively suppressed. The reasons for this are the greater flux of water and the increased momentum of the spray resulting from higher water pressures. With the full enclosure in place around the fuel source, extinguishment is possible only at the highest pressure (5.5 MPa), with the object on the spray centerline, and with at least $40 \%$ of the top area of the cabinet directly open to the spray. By contrast, similar fires in all geometric configurations can be successfully extinguished with $\mathrm{CF}_{3} \mathrm{H}$ as long as the concentrations in the chamber are close to those recommended in NFPA 2001.
\end{abstract}




\title{
PROTECTION OF DATA PROCESSING EQUIPMENT WITH FINE WATER SPRAYS
}

\author{
William Grosshandler, Darren Lowe \\ Kathy Notarianni, and William Rinkinen \\ Building and Fire Research Laboratory
}

\section{Background}

The application of fine water sprays (or mist) for fire suppression is not a new technology. Grinnell Corporation reports (Pepi, 1994) that "over the past 100 years or so, there has been on again, off again interest in the use of water mist for fixed fire extinguishing systems but apparently with no lasting impact on installation standards or commercial products with widely accepted application." The first NFPA standard for fine water spray (as opposed to sprinkler) systems for fire protection was adopted in 1939. Even in the foreword to this early document, it is stated (NFPA, 1947) that the principles involved in the use of fine water spray for fire suppression are not new, however, "devices to produce water spray have only recently become available." Many successful applications of fine water sprays in putting out fires in demonstrations, or in incidents encountered by fire departments have been reported in the technical literature, particularly that of the early 1950's (NFPA, 1952; Layman, 1953) when much research on gaseous agents was also being carried out. An excerpt from a 1955 Underwriters Laboratories study states the following (Underwriters Laboratory, 1955):

"There has been a considerable increase recently in the use of finely divided water, discharged from specially designed spray nozzles or automatic sprinklers, for extinguishing certain types of fires."

This statement could easily be made today as interest in the use of finely divided water for fire suppression purposes has peaked once again due to the phase out of the halon gases. The international interest in water mist technology, the substantial research and development effort that is ongoing, and the driving need for halon replacements contribute to this situation.

\subsection{Fine Water Sprays Compared to Sprinklers and Halon Systems}

The current standard, NFPA 15, "Standard for Water Spray Fixed Systems for Fire Protection," uses the term water spray to refer to the use of water in a form having a predetermined pattern, particle size, velocity, and density discharged from specially designed nozzles or devices. This definition does not provide a clear line of demarcation between conventional sprinklers, existing water spray systems, and more recently developed fine water spray, or mist, systems. While these are all water-based fire suppression systems, the predominant modes of extinguishment may differ as the volumetric mean diameter of the drops, $D_{v}$, decreases. $\left(D_{v x}\right.$ means that $x \%$ of the volume of water in the spray is contained in droplets whose diameter is less than this value.)

Sprinkler sprays contain a significant fraction of droplets large enough to penetrate the fire plume and wet the fuel surface. Drop size distribution measurements performed on the discharge from a standard $13 \mathrm{~mm}$ sprinkler resulted in a $\mathrm{D}_{v 9}$ of approximately $1250 \mu \mathrm{m}$ (Mawhinney, 1993). The predominant mode of extinguishment for conventional sprinkler systems is surface cooling.

Fine water spray systems are thought to extinguish the fire by mechanisms in addition to surface cooling. Depending on the nozzle design, its operating pressure and flow, some combination of the 
following mechanisms act to control, extinguish, or suppress the fire:

1) gas phase cooling, or heat extraction from the fire

2) reduced oxygen levels as water vapor displaces oxygen near the seat of the fire

3) radiant heat attenuation

4) flame stretch through momentum transfer from the spray

In some spray systems, direct contact of the water droplets with the burning fuel is also a factor.

A standard definition of what qualifies as a water mist fire suppression system has not been estab-

lished. ("Fine water spray" is taken to be synonymous with "water mist.") For the purposes of this report, systems which typically produce water droplets with volumetric mean diameters of 30 to $300 \mu \mathrm{m}$ and have water flows an order of magnitude or more less than a conventional sprinkler system are considered water mist systems. There are three basic types of nozzles used to produce a fine water spray: high pressure single orifice nozzles, low pressure single fluid nozzles, and air atomization nozzles. The high pressure nozzles generally operate at pressures of $10 \mathrm{MPa}$ and up, producing droplets whose mean diameters are in the range of 30 to $100 \mu \mathrm{m}$. Low pressure single fluid nozzles generally operate at pressures of 0.6 to $1 \mathrm{MPa}$. These low pressure nozzles produce a larger drop diameter than their high pressure counterparts. Drop diameters for the lower pressure nozzles are in the range of 200 to $300 \mu \mathrm{m}$. Air atomization nozzles generate droplets in the range of 100 to $200 \mu \mathrm{m}$ at low pressures, 0.6 to $1 \mathrm{MPa}$, but require a separate air supply in addition to the water supply.

Water is non-toxic, and systems using fine water sprays are available which are lower in cost than most systems using chemicals or patented mixtures. Water mist may provide more effective fire suppression than new gaseous flooding agents in applications such as deep-seated fires where the cooling capacity and penetration of water droplets may be an advantage if a portion of the droplets reach the base of the fire. Another application where water mist may be more effective in fire suppression is high temperature equipment surfaces such as found in machinery room fires and turbine enclosures. The fine water spray may cool the surfaces, potentially preventing re-ignition (Alpert, 1993).

Some advantages of water mist systems over conventional sprinkler systems include significantly reduced water flow demands, an order of magnitude less than a conventional sprinkler system. This translates into less potential for water damage and lower cost where the water supply is limited. Low water flows also provide a clear advantage in terms of space and weight requirements for the water supply. This is one reason for research and testing of water mists for protection of transportation systems such as ships and aircraft. Some flammable liquid spill fires that cannot be readily controlled with conventional sprinkler sprays due to splashing and spillage of the fuel may be extinguished by low momentum fine water sprays under certain conditions. Conventional sprinkler sprays may damage high temperature equipment surfaces from too rapid cooling due to high water fluxes and large droplet diameters.

Halon systems can be tailored to the space being protected, with the primary variable being the boiling point of the halocarbon chosen as the extinguishing agent. $\mathrm{CF}_{2} \mathrm{ClBr}$ (halon 1211) boils at $-4{ }^{\circ} \mathrm{C}$, and normally exits the distribution system as a liquid stream or spray, and thus can be directed like water to the base of a fire. It has the advantage over water that it evaporates quickly, leaving little residue and minimizing collateral damage to adjacent equipment that is not on fire. Halon $1301\left(\mathrm{CF}_{3} \mathrm{Br}\right)$ is stored as a liquid at high pressure but boils at $-58^{\circ} \mathrm{C}$ at atmospheric conditions. It emerges from its distribution system as a gas or fine mist which quickly vaporizes. Halon 1301 works by filling the room and being entrained into the fire, where it chemically inhibits the combustion reaction. Because it is designed to vaporize fully and flood the room, it can attack a fire anywhere, but works most efficiently when ventilation can be minimized before the agent is released. Like halon 1211, halon 1301 causes no significant collateral damage to the equipment being protected whether discharged during a fire or in case of a false alarm. 


\subsection{Fire Protection Needs for Data Processing Equipment}

Data processing equipment is used in all aspects of modern commerce, and its value goes far beyond the replacement costs of the hardware. The largest loss in a computer fire is from the interruption of service, which can be devastating, for example, to transportation systems, communications networks, security operations, and the banking industry.

Of the four hundred fires reported in computer and data processing centers in the US from 1981 through 1985 , over $60 \%$ began in equipment or spaces other than the computers themselves (Taylor, 1989). The largest single cause (30\%) was attributed to unspecified electrical distribution systems problems. The electrical connections are much more likely to be responsible rather than the internal computer equipment components (Simmons, 1990). The implication is that fire protection strategies for data processing equipment must accommodate the possibility that the fire begins elsewhere and propagates towards the computer equipment.

Computer rooms, themselves, are of specialized design, creating unique fire hazards. In addition to the possibility of fire spreading from the neighboring areas as mentioned above, the Allianz Risk Service (1991) describes the risks associated with power and data cables located in the under-floor areas; the combustible paper and plastics (e.g., furniture and operation manuals) in peripheral equipment intimately tied to operations; and the technical equipment including the computer cabinets, power distribution panels, and air conditioning units. The above-ceiling area also posses a unique fire protection problem, but there is less likelihood that this area would house the source of ignition.

Price (1990) reviewed the basic components of fire protection in computer rooms, assuming an existing halon system was available. Simmons (1990) stressed the point that no one system fits all computer room applications, and that an unbiased analysis of the alternatives is not always forthcoming. A recent article in the Record (1993) promotes an integrated approach to risk management in the posthalon era. This same theme is maintained by Bryant (1993). He discusses the role of portable extinguishers, $\mathrm{CO}_{2}$ flooding systems for unoccupied or evacuated spaces (i.e., under-floor or in-cabinet deployment), high expansion foams, and sprinkler systems. Fluorocarbons such as $\mathrm{CF}_{3} \mathrm{H}(\mathrm{HFC}-23), \mathrm{C}_{3} \mathrm{~F}_{8}$ (FC-218), and $\mathrm{C}_{3} \mathrm{~F}_{10}$ (FC-3-1-10) and inert gas mixtures (e.g., Inergen, $\mathrm{N}_{2} / \mathrm{A} / \mathrm{CO}_{2}$ ) are mentioned as candidates for room flooding applications.

The conventional belief that one should not put water on an electrical fire is still held by many end-users. The fire protection community, however, has for a long time now recommended sprinklers in computer and other electronics rooms with the belief that the water damage is certainly no worse than the damage from an uncontrolled fire. The technology to dry out and recommission electronic equipment has improved dramatically over the past several years. Water mist systems, if designed optimally, will take less water than sprinklers to extinguish the fire. It remains to be seen if the electronic equipment can continuously operate during discharge of a water mist system.

\subsection{Research Objective and General Approach}

The design and operation of some current and envisioned fine water spray systems were described in a recently held workshop (Notarianni and Jason, 1993). An analysis of the papers presented at the workshop and the ensuing discussions leads to the following truism: fine water droplets behave significantly differently from coarse water droplets, and gases behave significantly differently from fine water droplets. Hence, it is difficult to extrapolate the behavior of a water mist system from the performance of either a sprinkler or a halon system.

The protection of computer rooms and data processing equipment is an area in which the positive attributes of halon-type systems and the drawbacks of conventional sprinklers are obvious. The total ban on new halon production starting in January, 1994, removes this seemingly perfect suppressant as an 
option, pointing to a clear need to find one or more suitable replacement fire suppressants (Harrington, 1993). A water spray system is an attractive candidate for replacing halon 1301, but the dynamics controlling the transport of the liquid water droplets are different from the dynamics of a prevaporized gas; hence, the problem is to determine the applicability of a liquid spray system in an environment currently protected with a gaseous agent.

The long-range goal of this research is to establish the limitations of a water spray to protect data processing equipment from the threat of a fire. The mechanisms of suppressing fires propagating outside of computer equipment is similar to suppressing fires in offices and hotels. Tests of the suppression of a fire within an electronics cabinet using multiple in-cabinet nozzles have been reported by Hills et al. (1993). The specific topic on which our efforts were concentrated was the suppression of an in-cabinet fire with an externally located nozzle. In addition to providing evidence of performance (or lack of it) under the test conditions examined, the current work also provides the first step towards predicting the unwanted penetration of water sprays into adjacent cabinets which are not on fire.

The approach to obtain the first year's objective has involved the following steps:

1. Refine our understanding of the problem by reviewing the literature and talking with the computer and spray systems industry.

2. Identify a representative cabinet geometry, fire threat, and spray system.

3. Design a generic test article and experimental protocol to assess the impact of the cabinet geometry on suppression.

4. Conduct the experiments in a controlled environment, and duplicate runs to demonstrate reproducibility.

5. Display data and analyze results.

The experimental facility and operating procedure are described in the next section. The results are presented in section 3, followed by our interpretation. The final section presents conclusions and makes recommendations for further work. 


\section{Experimental Facility}

A new laboratory has been built to allow pilot-scale testing of different water spray systems and equipment fires. Development of the facility has required the selection and design of a targeted electronics cabinet, an enclosure to contain the spray, the water spray delivery system, a gaseous agent suppression system, a control system, and instrumentation for measurement and data acquisition.

\subsection{Generic Electronics Cabinet}

The structure of electronics cabinets used in data processing is as varied as the number of manufacturers and their multiple product lines. The sizes of individual cabinets range from small enough to sit on a desk top to large enough to fill a small room. They can be free-standing or built-in. They can contain high voltage power supplies and CRTs, or low power CPUs; mechanical equipment such as pumps, fans, disk drives and printing devices; or circuit boards with no moving parts. The internal architecture can be randomly cluttered, or primarily parallel plate circuit boards placed horizontally or vertically. The cooling system can be natural convection, forced air, or forced liquid. The air-cooled systems can have vents on the top, sides or bottom.

The success of a particular water spray fire protection system will differ depending upon the actual cabinet design and its contents. The scope of this investigation has been limited to a generic data processing unit with the following attributes:

- small size cabinet

- circuit boards placed vertically

- forced-air cooled with vents on the top and/or bottom

- primary fuel is the circuit board

- ignition is due to a local overheated condition on the board or from organic material at bottom of cabinet

A sketch of the mock computer cabinet designed to simulate the generic system is shown in Fig. 1. The overall dimensions are $0.5 \mathrm{~m}$ wide, $0.4 \mathrm{~m}$ high and $0.2 \mathrm{~m}$ deep. It was constructed primarily from $6 \mathrm{~mm}$ thick aluminum plates bolted along the vertical corners. The upper surface was removable to allow the installation of tops of different designs and per cent open area. The cabinet is free-standing on legs that are $50 \mathrm{~mm}$ long, allowing air to flow freely into or out from the bottom. Three cooling fans, 0.11 $\mathrm{m}$ in diameter, are mounted horizontally, with the lower surface $50 \mathrm{~mm}$ above the floor and the upper surface $50 \mathrm{~mm}$ below the bottom of the internal circuit boards.

Up to six aluminum plates, $3 \mathrm{~mm}$ thick, were placed parallel to each other and vertically inside the cabinet on etiher side of the center plate, which was the fuel source and made of $3 \mathrm{~mm}$ thick poly(methyl methacrylate) (PMMA). A schematic of the flammable circuit board and the burner used for ignition is shown in the lower portion of Fig. 2. Natural gas ignited by a spark supplied a uniform line source for starting the simulated circuit board fire. The space in between the adjacent boards was either 25 or $50 \mathrm{~mm}$, providing a large aspect ratio cross-section which encouraged a two-dimensional fire and flow field. The front and one side vertical panel were made from PMMA to permit visual observation of the internal fire and the suppression process.

Initial suppression studies were conducted with a $0.2 \mathrm{~m}$ square portion of the PMMA circuit board completely open to the environment. The sample holder and igniter for these unobstructed tests are shown at the top of Fig. 2. 


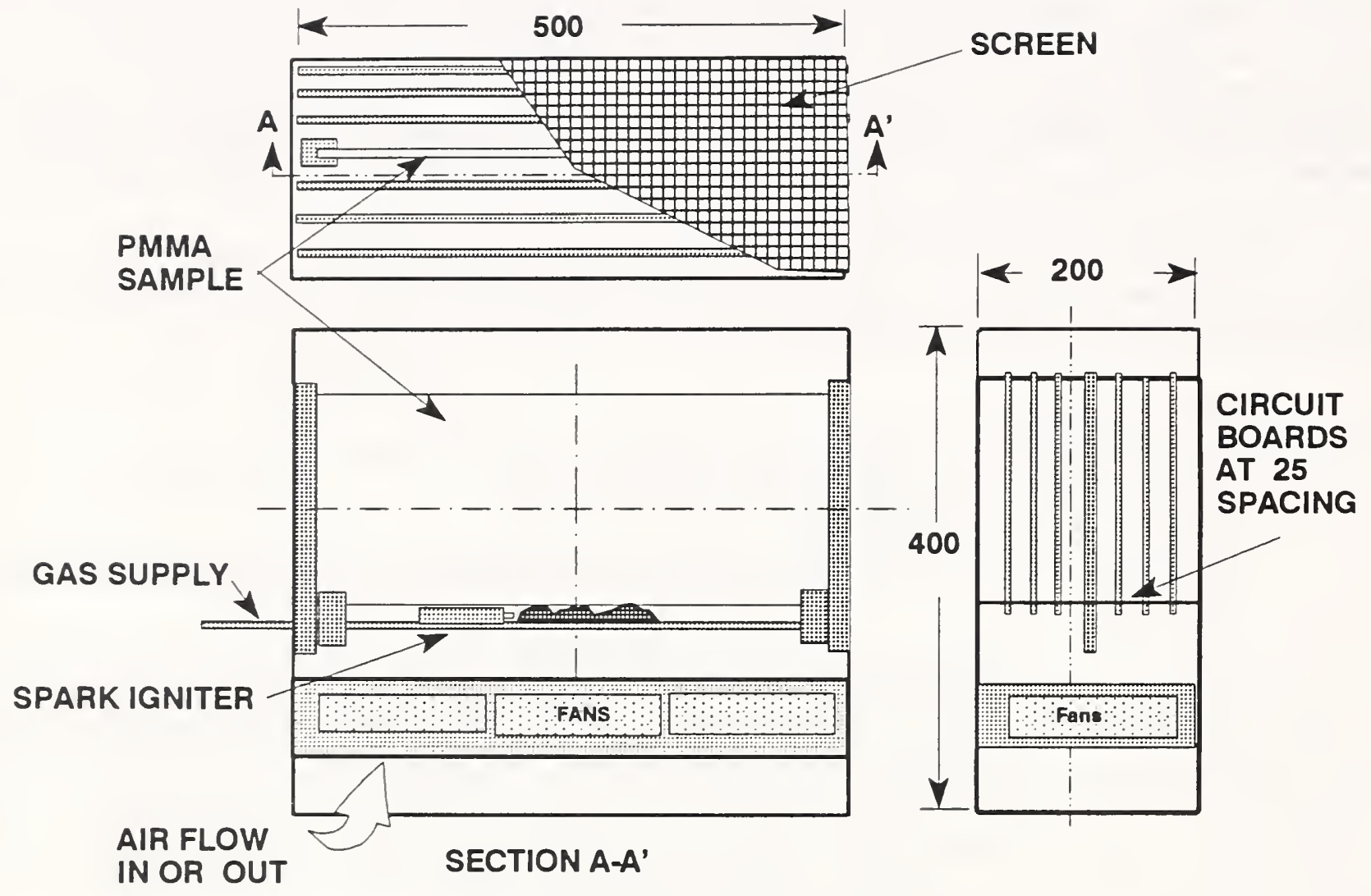

Figure 1. Schematic of mock computer cabinet (dimensions in $\mathrm{mm}$ ). Center "circuit board" is PMMA; all others are $3 \mathrm{~mm}$ thick aluminum plates. 


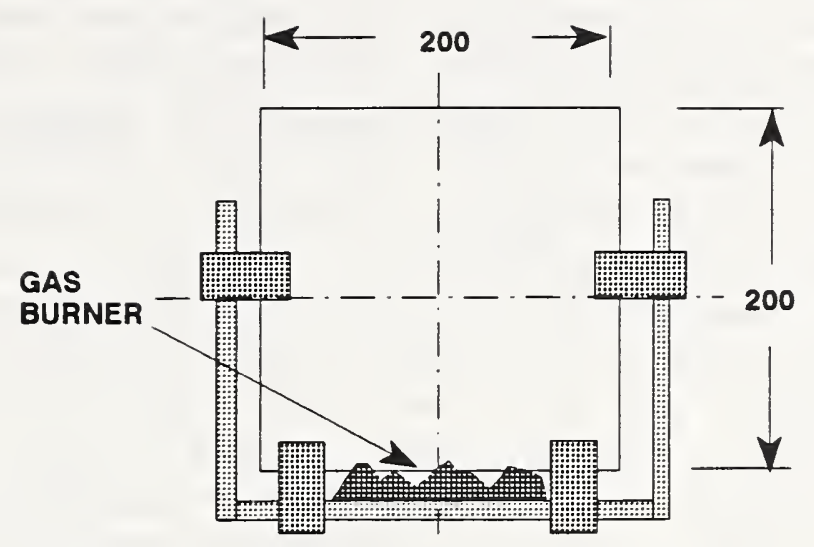

$3 \mathrm{~mm}$ THICK PMMA SAMPLE AND HOLDER FOR UNOBSTRUCTED TESTS

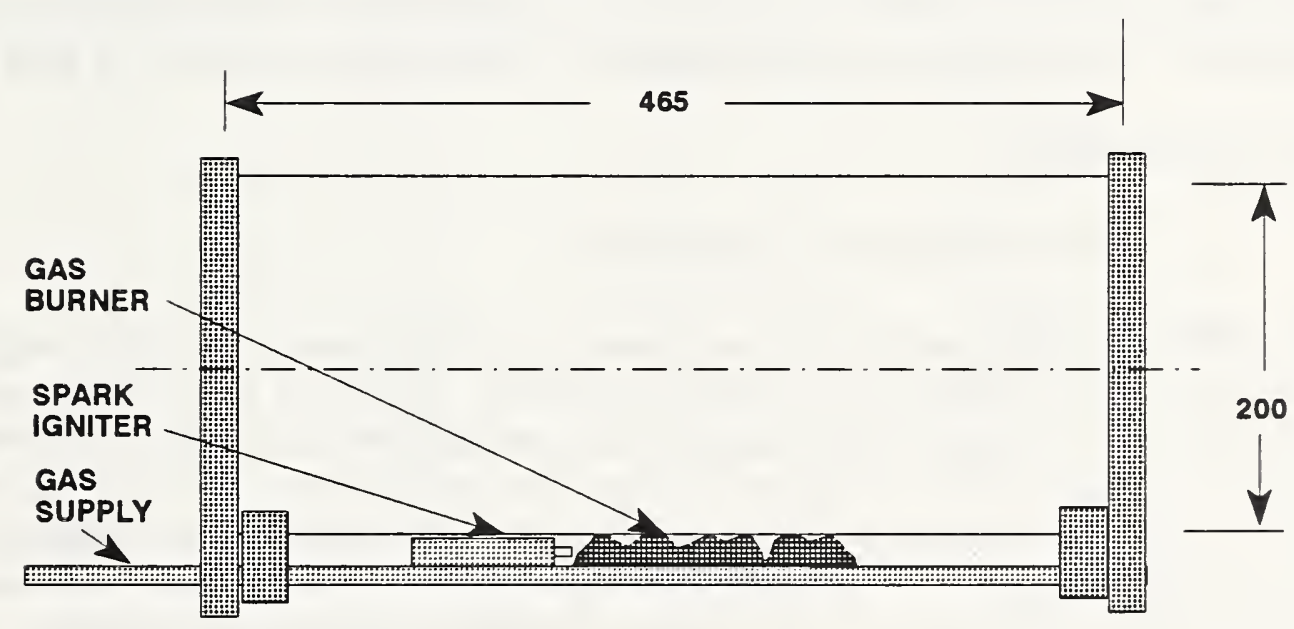

\section{$3 \mathrm{~mm}$ THICK PMMA SAMPLE AND HOLDER FOR SUPPRESSION TEST INSIDE MOCK COMPUTER CABINET}

Figure 2. Sketch of poly(methyl methacrylate) "circuit board" fuel and ignition system for the unobstructed (upper) and in-cabinet (lower) fire experiments. Dimensions are in $\mathrm{mm}$. 


\subsection{Spray Chamber}

A spray chamber was built under an existing canopy which is an integral part of an exhaust system. The hood was used to remove the water mist as well as products of combustion at the end of each experiment. Figure 3 shows the dimensions (in $\mathrm{mm}$ ) of the enclosure. The interior is $1.65 \mathrm{~m}$ wide, $0.91 \mathrm{~m}$ deep and $2.0 \mathrm{~m}$ high. The approximately $3.2 \mathrm{~m}^{3}$ enclosure was lined with overlapping aluminum sheets. Silicon sealant was applied to the joints to prevent water leaks. The floor was an aluminum pan which was deep enough to hold all of the water from a single test. A wet/dry vacuum was used to remove water from the floor pan between experiments. To give greater visibility of the experiment, full view storm window doors covered the enclosure, two in front and one on the right side. The left side was used for entry of the equipment cables and plumbing.

Five water spray nozzles were located at the top of the enclosure just below the canopy hood, one in the center and the others at the tips of an H-pattern. Water flow to each was controlled with individual ball valves, supplied through $12 \mathrm{~mm}$ stainless steel tubing from a steel storage reservoir manufactured from a $3 \mathrm{~A}$ size gas cylinder. An in-line strainer protected the spray nozzles from contaminating particulates. High pressure nitrogen was used to push the water out of the storage tank through a dip tube running the depth of the cylinder. A third tank contained high pressure air. This was used for nozzles that required air atomization. Figure 4 is a layout of the water piping system, and Fig. 5 shows how the storage tank was filled between runs using a filtered domestic water supply.

The flow system used to deliver the gaseous suppressant is shown in Fig. 6. The air cylinder in Fig. 4 was replaced with a $\mathrm{CF}_{3} \mathrm{H}$ supply tank that had a room temperature vapor pressure of about $4 \mathrm{MPa}$. The gas was piped through the air line, through a metering orifice, and to a nozzle located in the center of the room. The isentropic expansion of the gas within the storage bottle cooled the remaining mass and decreased the vapor pressure accordingly, as seen in Fig. 7.

The behavior of two different size air-assisted nozzles and two different size pressure-jet nozzles were investigated. The flow ratings and characteristics of the nozzles are shown in table 1.

\subsection{Instrumentation}

\subsubsection{Flow and pressure measurements}

Water pressure measurements were made using a thin film pressure transducer coupled with a high performance strain gauge indicator. The pressure transducer provides a 4-20 mA output signal that is proportional to the pressure (liquid or gas) applied to the sensing head. By using a water pressure snubber fitting attached to the inlet of the transducer, damage from fluid hammer and surge effects is avoided. The strain gauge indicator, which also provides excitation to the sensing element, is capable of converting the output to user-specified pressure units. Response curves for the four pressure transducers are shown in Fig. 8. The overall time response of the pressure transmitter/indicator combination is $80 \mathrm{~ms}$. Air pressure measurements may also be made with the use of an air snubber fitting which is similar to the water snubber. This fitting protects the device from sudden surges in air pressure. The analog output signal from each pressure transducer is connected to the central data acquisition system. The manufacturer specified accuracy of the pressure tranducers is $\pm 0.4 \%$ full-scale. From repeat runs, it is estimated that the recorded pressure is within $\pm 0.1 \mathrm{MPa}$ of the actual pressure during the discharge process.

Water flow measurements were made using a turbine flowmeter. The angular velocity results in the generation of an AC signal which is related directly to the flow. A set of integral flow straightening tubes minimizes the effects of upstream flow turbulence. The range of this meter is 1.32 to $13.2 \mathrm{l} / \mathrm{min}$ at pressures from 0 to $6.9 \mathrm{MPa}$-g. The calibration curves shown in Fig. 9 relate the actual flow rate measured by the device and the nozzle manufacturers specifications. The analog output signal from the 

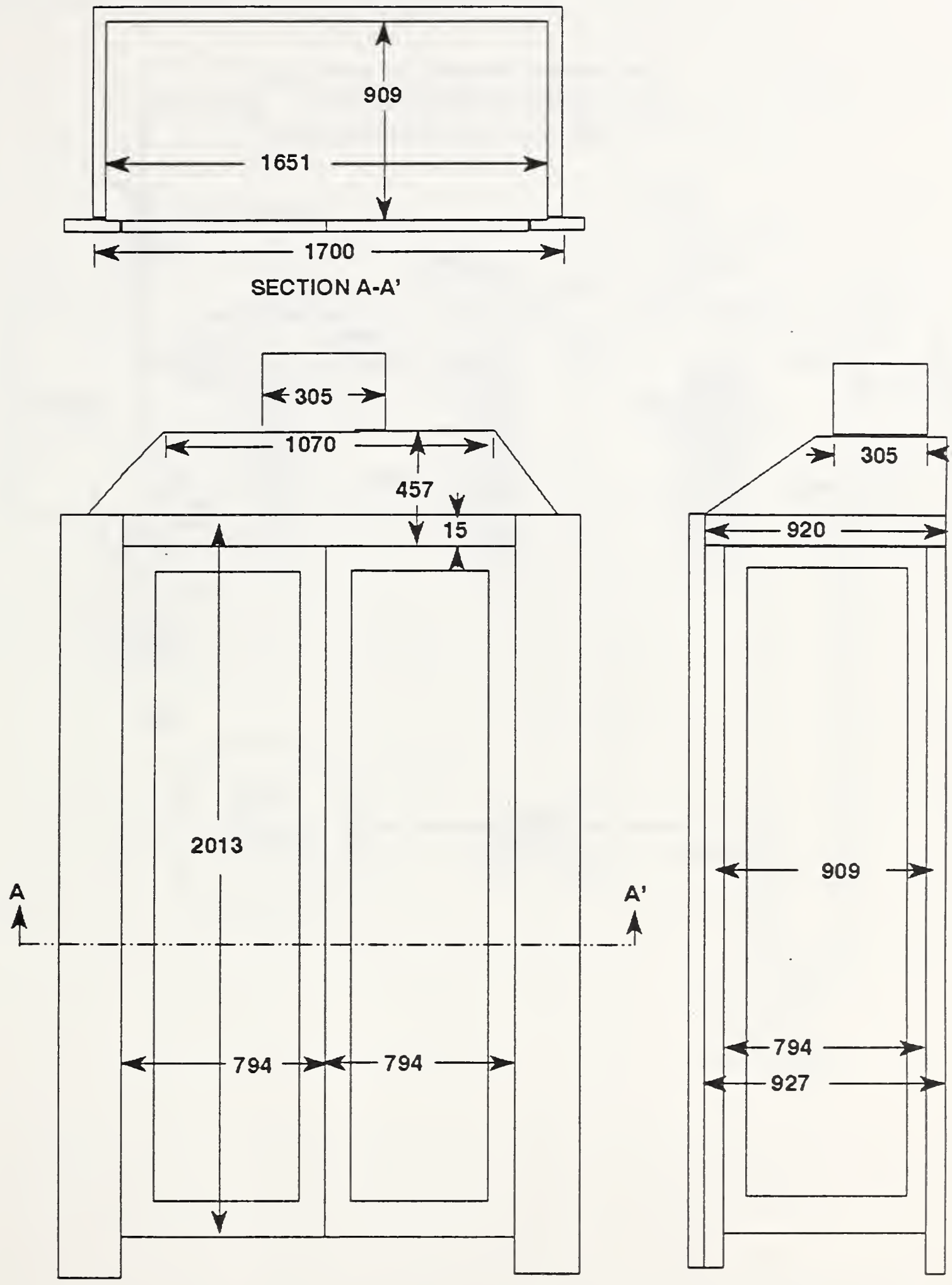

Figure 3. Dimensions ( $\mathrm{mm}$ ) of chamber used to confine mock computer cabinet and water spray system 


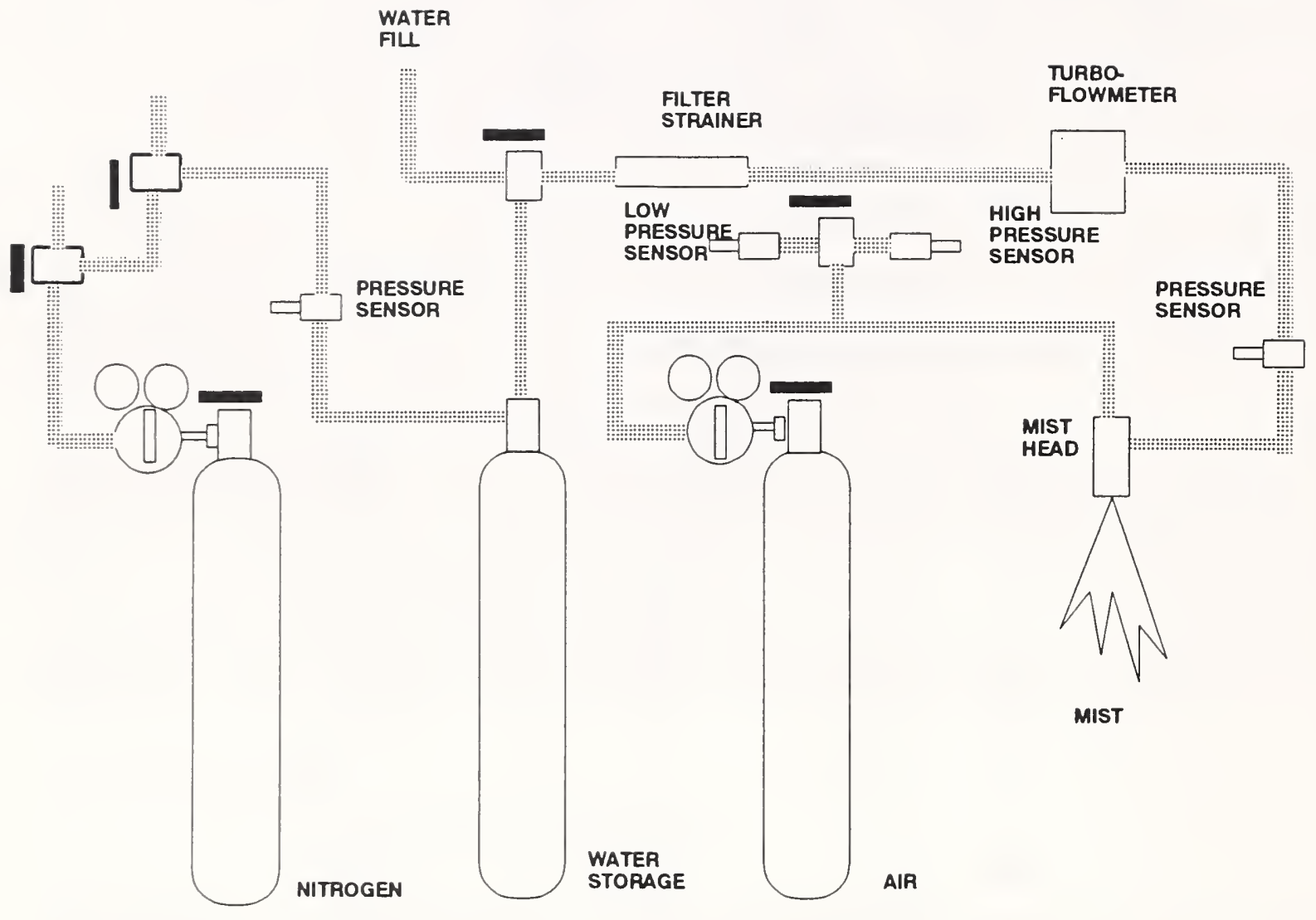

Figure 4. Schematic of gas and water storage and delivery system 


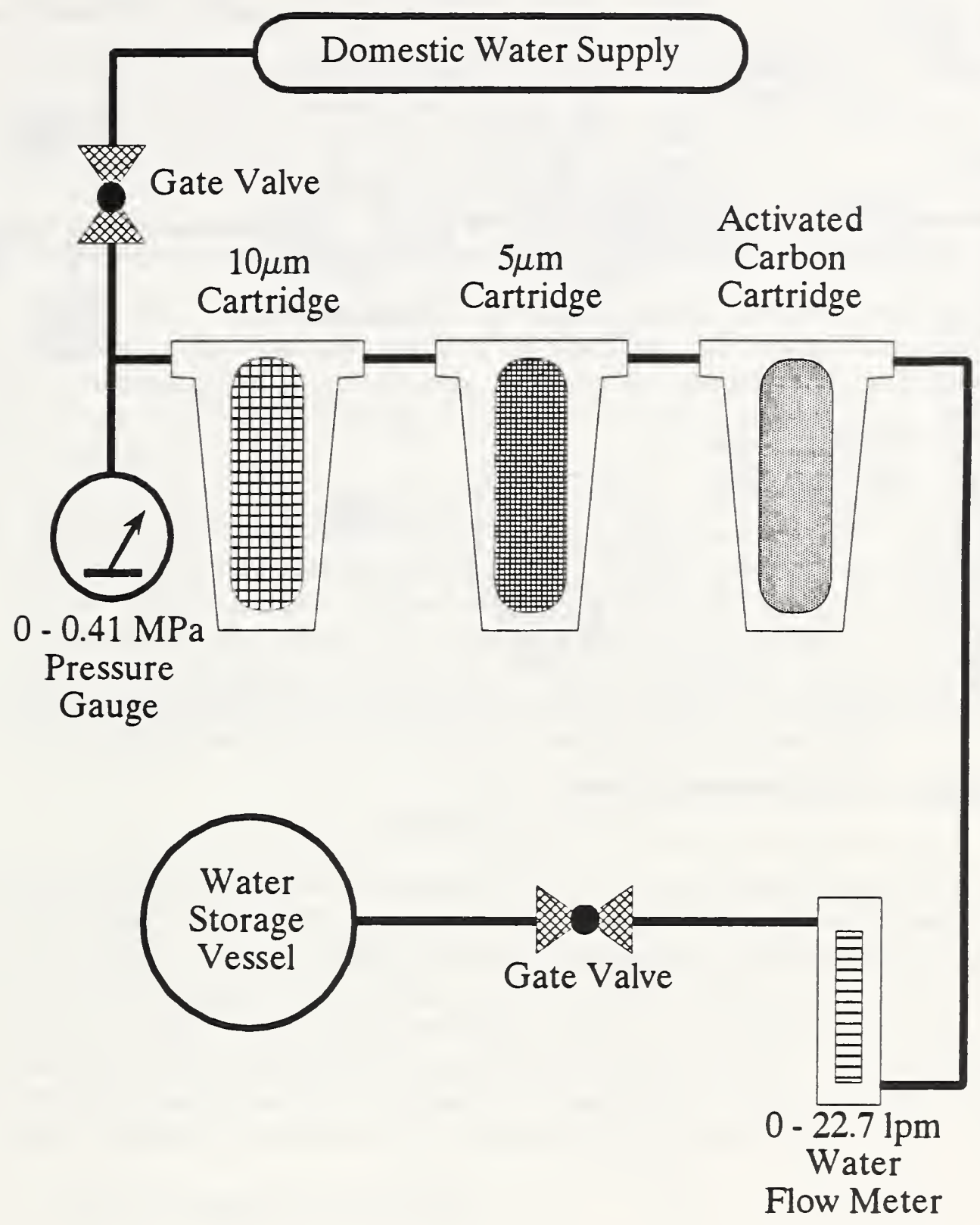

Figure 5. Schematic of water re-filling system 


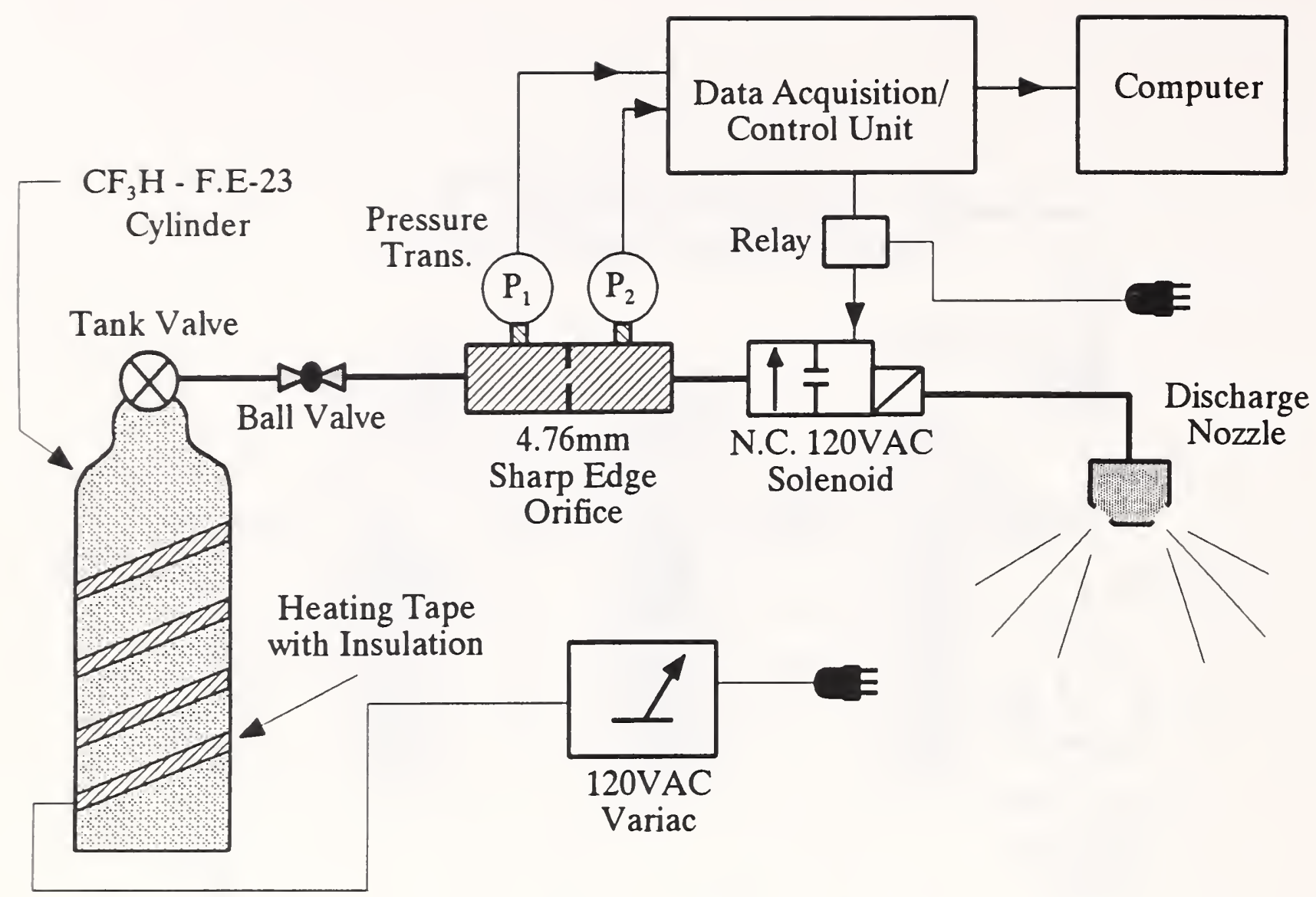

Figure 6. Schematic of $\mathrm{CF}_{3} \mathrm{H}$ metering system.

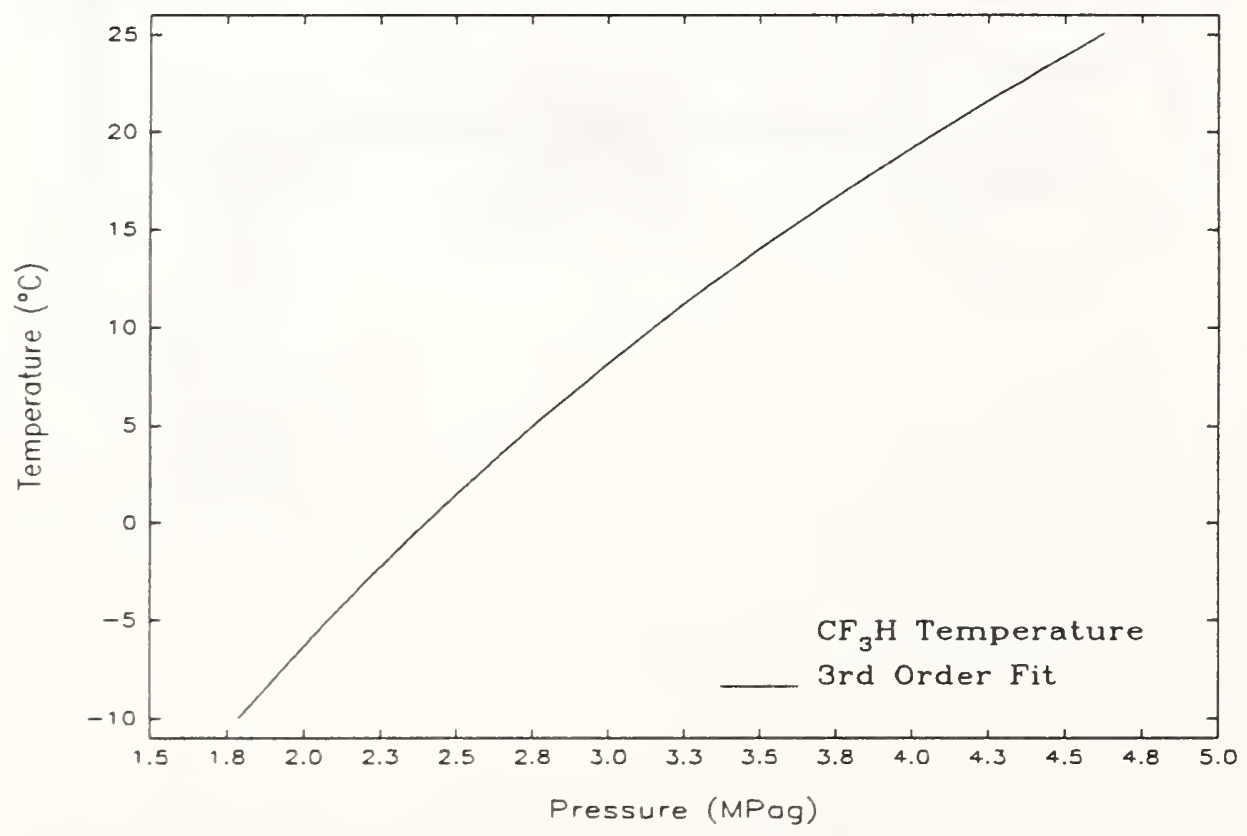

Figure 7. Temperature dependence of $\mathrm{CF}_{3} \mathrm{H}$ vapor pressure. 
Table 1. Characteristics of fine water spray nozzles

\begin{tabular}{|c|c|c|c|c||}
\hline Type (designation) & $\begin{array}{c}\text { Water Pressure, } \\
\mathrm{kPa}\end{array}$ & $\begin{array}{c}\text { Water Flow, } \\
l / \mathrm{min}\end{array}$ & $\begin{array}{c}\text { Air Pressure, } \\
\mathrm{kPa}\end{array}$ & Cone Angle \\
\hline air-assisted (AA-L) & $340-520$ & 3 & $340-520$ & $>90^{\circ}$ \\
\hline air-assisted (AA-H) & $340-520$ & 10 & $340-520$ & $>90^{\circ}$ \\
\hline pressure-jet, hollow cone (PJ-L) & $210-6900$ & $0.32-1.9$ & -- & $73^{\circ}-81^{\circ}$ \\
\hline pressure-jet, hollow cone (PJ-H) & $210-6900$ & $0.76-4.4$ & -- & $85^{\circ}-90^{\circ}$ \\
\hline
\end{tabular}

flowmeter is 0 to $5 \mathrm{VDC}$. Upstream from the flow meter is an in-line filter which provides protection from large particulate matter that may appear in the water line. This signal from the flowmeter is also connected to the central data acquisition system. Because the pressure drops after the solenoid valve is opened, the reported water flows are average values that are estimated to be within $\pm 0.1 \mathrm{l} / \mathrm{min}$ from one experiment to the next.

The flow of gaseous agent was determined from the pressure drop across a $4.76 \mathrm{~mm}$ diameter sharp edge metering orifice and two electronic pressure transducers, as shown in Fig. 6. Solenoid activation was controlled by the data acquisition system. The gas within the bottle cooled as it expanded during the delivery period, so that it became necessary to heat the $\mathrm{CF}_{3} \mathrm{H}$ cylinder with heating tape to maintain a reasonably constant pressure. By measuring the upstream pressure, $\mathrm{P}_{1}$, and by extracting the temperature from Fig. 7, the density of agent $(\rho)$ could be estimated from the ideal gas equation of state. The mass flow was determined from the following equation, where $Y$ is the expansion factor $(\approx 1), \mathrm{k}$ is the flow coefficient taken as 0.63 , and $\mathrm{A}$ is the cross sectional area of the orifice:

$$
m^{\prime}=Y k A \sqrt{2 \rho\left(P_{1}-P_{2}\right)}
$$

The instantaneous mass flow as a function of time for two different trial runs is plotted in Fig 10. The flow into the spray enclosure decreased with time because of the adiabatic expansion of the material within the $\mathrm{CF}_{3} \mathrm{H}$ storage vessel. The spike of mass at the beginning of the injection was expected because initially the downstream pressure dropped more quickly than the upstream value. The spike which appears in trial 3B when the solenoid valve closes (see bottom right, Fig. 10) cannot be physical, and is attributed to the finite response of the solenoid valve and the data acquisition process. The reported mass flows are based upon the quasi-steady conditions between the opening and closing transient, which are estimated to be as much as $25 \%$ below the actual mass added during the entire interval.

\subsubsection{Droplet Size and Velocity}

Average particle diameter and velocity in the horizontal and vertical directions were made using an Aerometrics* Phase Doppler Particle Analyzer (PDPA). When water droplets pass through the intersection of two incident laser beams lying in the horizontal and vertical planes they scatter the incident

- Certain commercial products are identified in this report in order to adequately specify equipment used. Such identification does not imply recommendation from the National Institute of Standards and Technology, nor does it imply that this equipment is the best available for the purpose. 


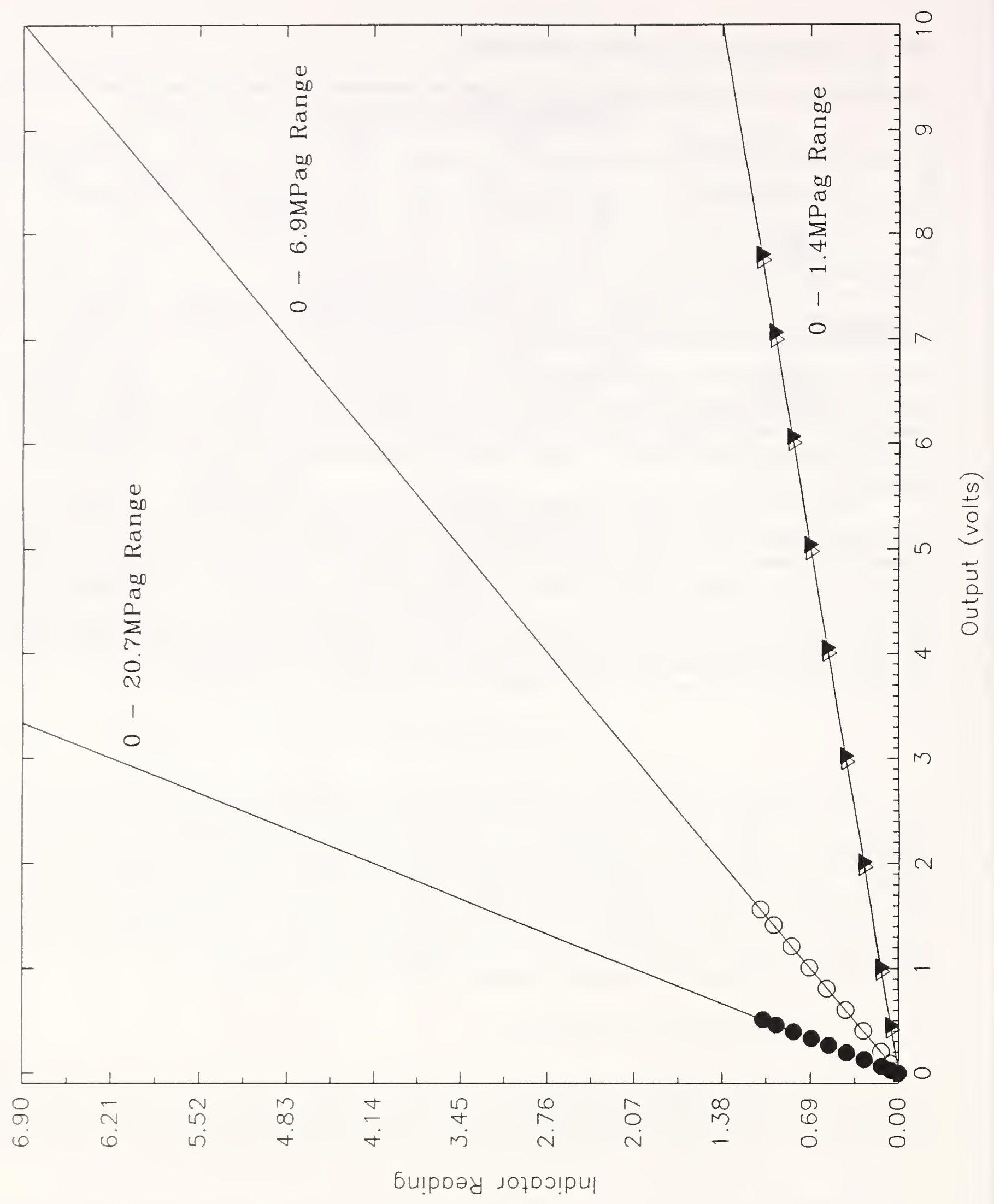

Figure 8. Calibration curves for electronic pressure transducers. 


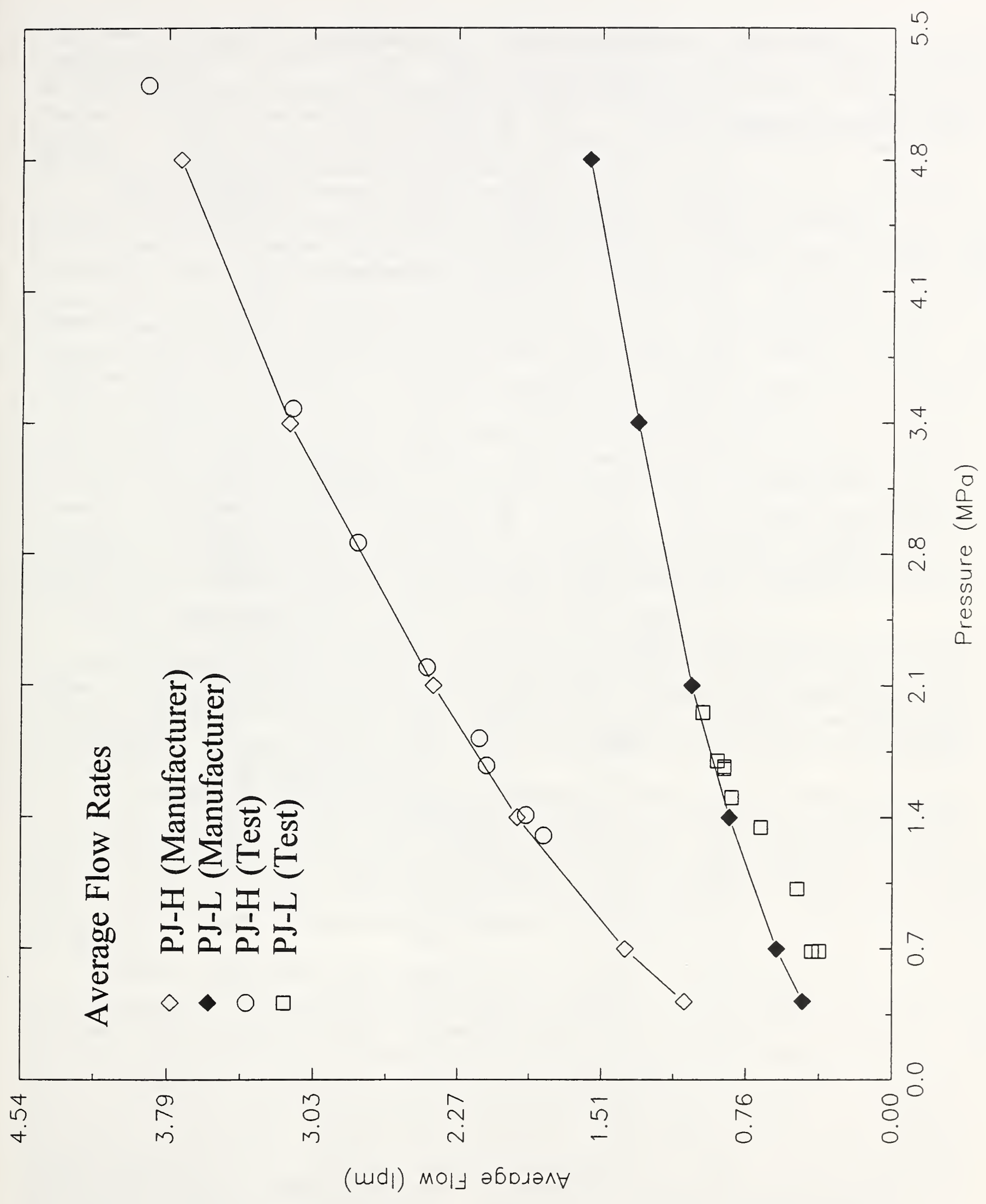

Figure 9. Actual water flow curves compared to manufacturer's specifications. 

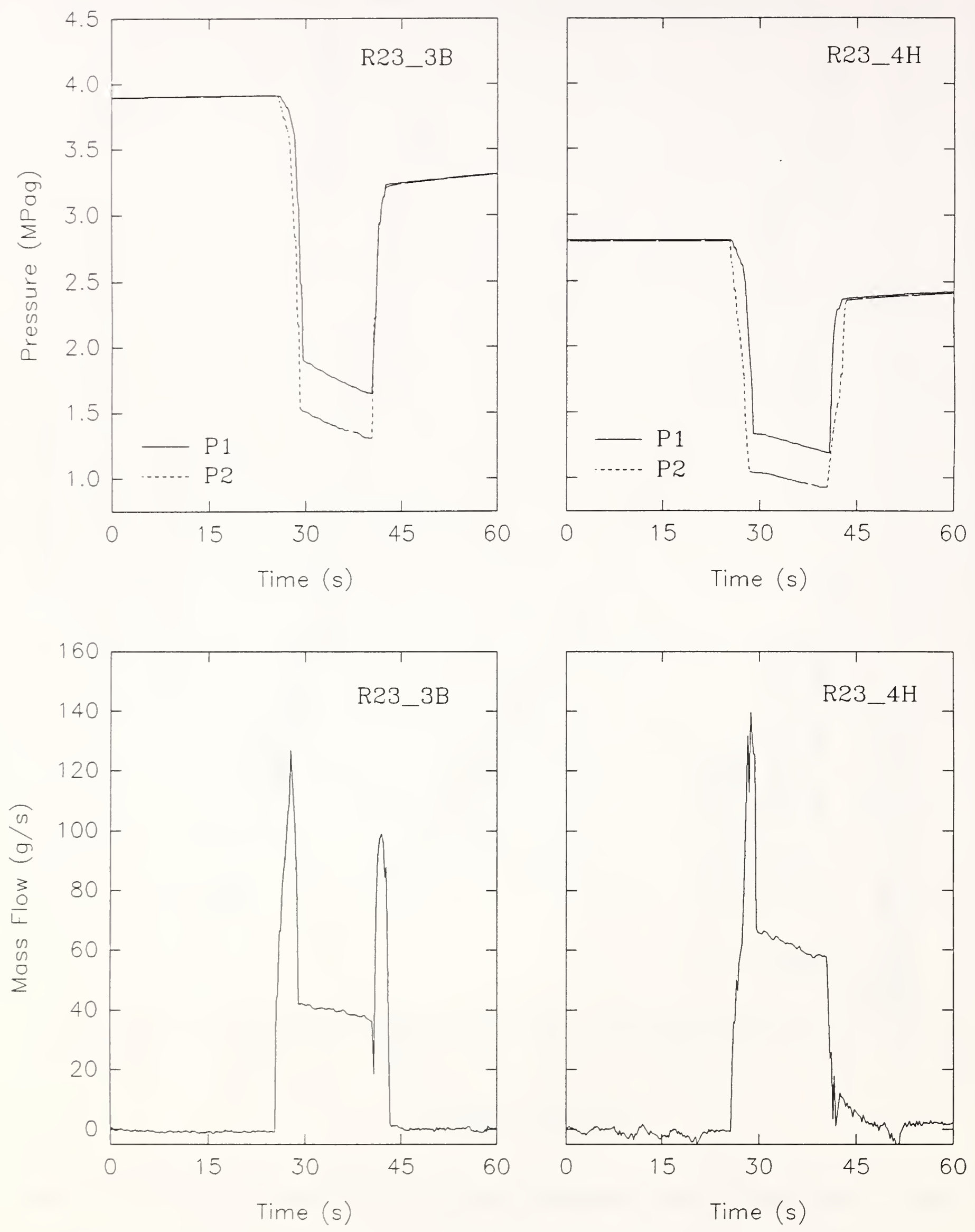

Figure 10. Pressure drop through $\mathrm{CF}_{3} \mathrm{H}$ metering orifice and estimated corresponding mass flow. 
light beams in proportion to the square of their diameter (Rudoff et al., 1991; Bachalo, 1988). The intersection of the beams, called the probe volume, can be approximated as a slice of a cylinder, the width and angle of which are determined by the receiver aperture, focal length, and angle. The light intensity decreases in a Gaussian fashion from the center of the cylinder, making the diameter of the probe volume dynamic. For fixed receiving optics the effective diameter varies with particle size, laser power, obscuration, and signal amplification (Bachalo and Houser, 1984).

The phase Doppler instrument measures the time-of-arrival of each particle in the probe volume and follows the particle as it passes through the adjacent fringes, permitting a calculation of velocity. Only one particle can be present in the probe volume at a time, it must be spherical, and it must pass close enough to the center of the volume to produce a valid signal. The percentage of valid signals is computed by the instrument and is one measure of how reliable the data are likely to be. By keeping track of the number of particles and the total sampling time, the transit time of the particles passing through the a fixed probe volume can be used to generate the number density (Aerometrics, 1993b). In addition, the signal processor has the capability of measuring the scattered light amplitude, signal period and phase (Aerometrics, 1993a). This feature is important in providing the necessary information to automatically adjust the photomultiplier tube (PMT) high voltage when conditions of the spray, such as pressure or location relative to the nozzle, have been changed. A bias towards one particular size class over another can occur if the voltage is set improperly. For a monodispersed spray, the computed velocity and particle diameter are unaffected as long as the signal received by the PMT is within its dynamic operating range (i.e., greater than threshold and less than saturation). In the current experiment, a voltage set too low resulted in an increase of around $20 \mu \mathrm{m}$ in the average droplet diameter, but no significant change in average velocity. An indication that the voltage was improperly set following a change in spray conditions was a large decrease in the number of counts per sampling time interval.

Histograms for velocity and particle diameter can be displayed after the data are collected and processed. Geometric mean diameters and Sauter mean diameters (SMD) are also calculated at this point. Figure 11 contains sample data collected for a representative test. Correlations including diameter versus velocity and velocity in vertical direction versus velocity in the horizontal direction can be plotted to help in the analysis. A sample correlation and a plot of the median size and best-fit Rosin-Rammler comparison are shown in Figs. 12 and 13.

The optics for the PDPA are mounted on aluminum rails which lie in an L-shaped configuration within the test enclosure. (See Fig. 16.) Height adjustments are made by adding or subtracting blocks located under the corners of the rail system. The mock computer cabinet is positioned along the centerline below the nozzle and the PDPA optics are then positioned in one of two measurement locations. The desired measurement locations are $0.20 \mathrm{~m}$ and $0.03 \mathrm{~m}$ above the article's top. These measurement locations provide particle diameter and velocity information with respect to changes in air flow magnitude and direction.

Protection of the PDPA optics during the water mist tests is of critical importance. Since the device measures light refraction through a water droplet to obtain the diameter, moisture or fine mist that condenses on the receiver lens will greatly distort the results. Moisture collecting on the transmitter lens will cause prismatic scattering of the laser beams and result in problems of beam intensity and intersection angles. This problem is minimized by attaching a small plastic cylinder with an aperture large enough to allow the beam to pass directly to the housing of the receiver and transmitter. A small flow of compressed air $(50 \mathrm{ml} / \mathrm{min})$ is injected into the cylinder to create a positive pressure, thus preventing airborne mist droplets from settling on lens surfaces. The cylinder is also large enough to prevent larger particles from impinging directly on the lenses. This preventative measure is generally effective in most cases where the water mist exposure is less than 2 minutes. A degradation of instrument performance is easily identified by a large drop in the total number of counts during the sampling period and a decrease in the percent valid. 


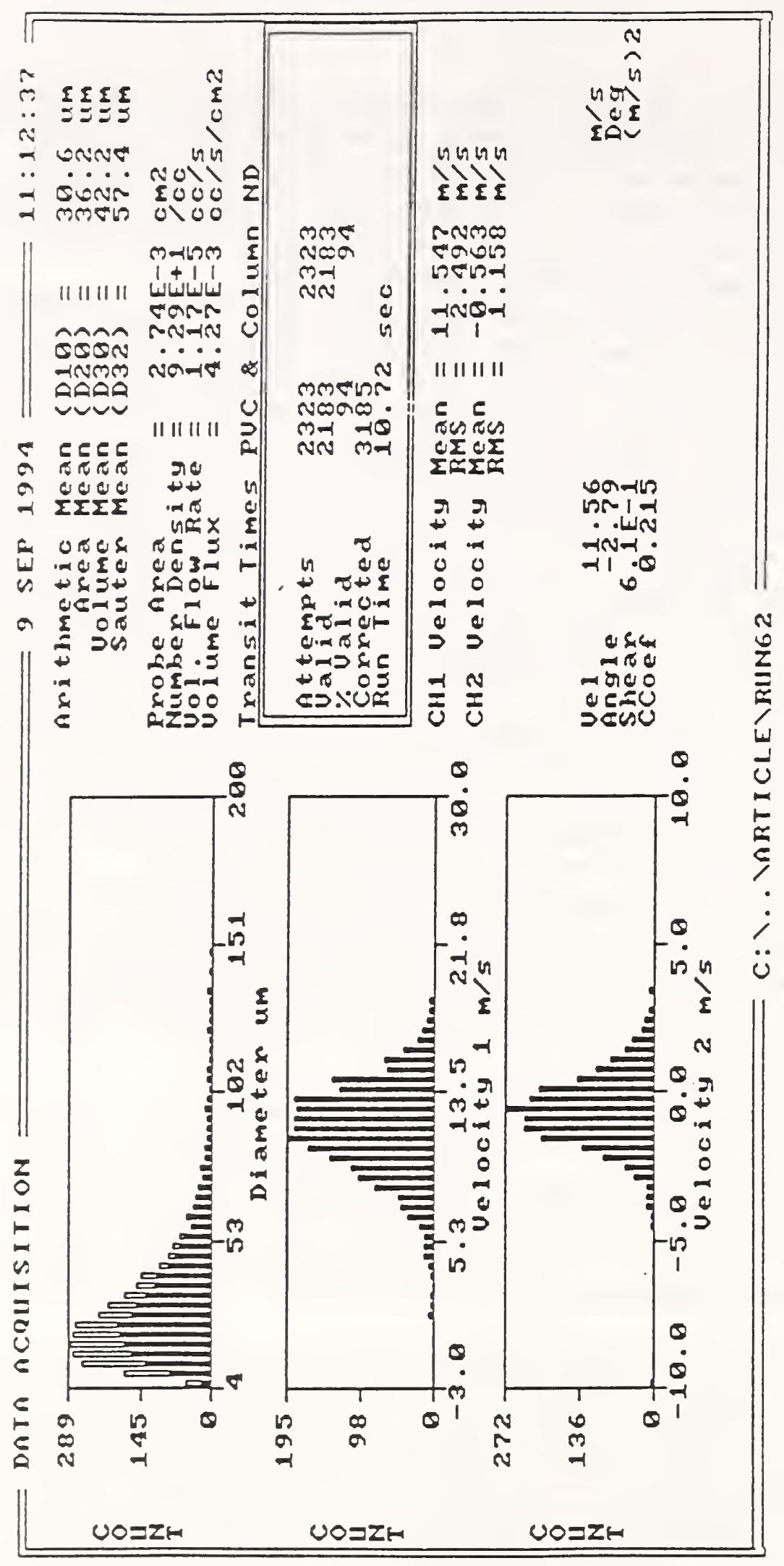

Figure 11. Sample PDPA data collection screen. 


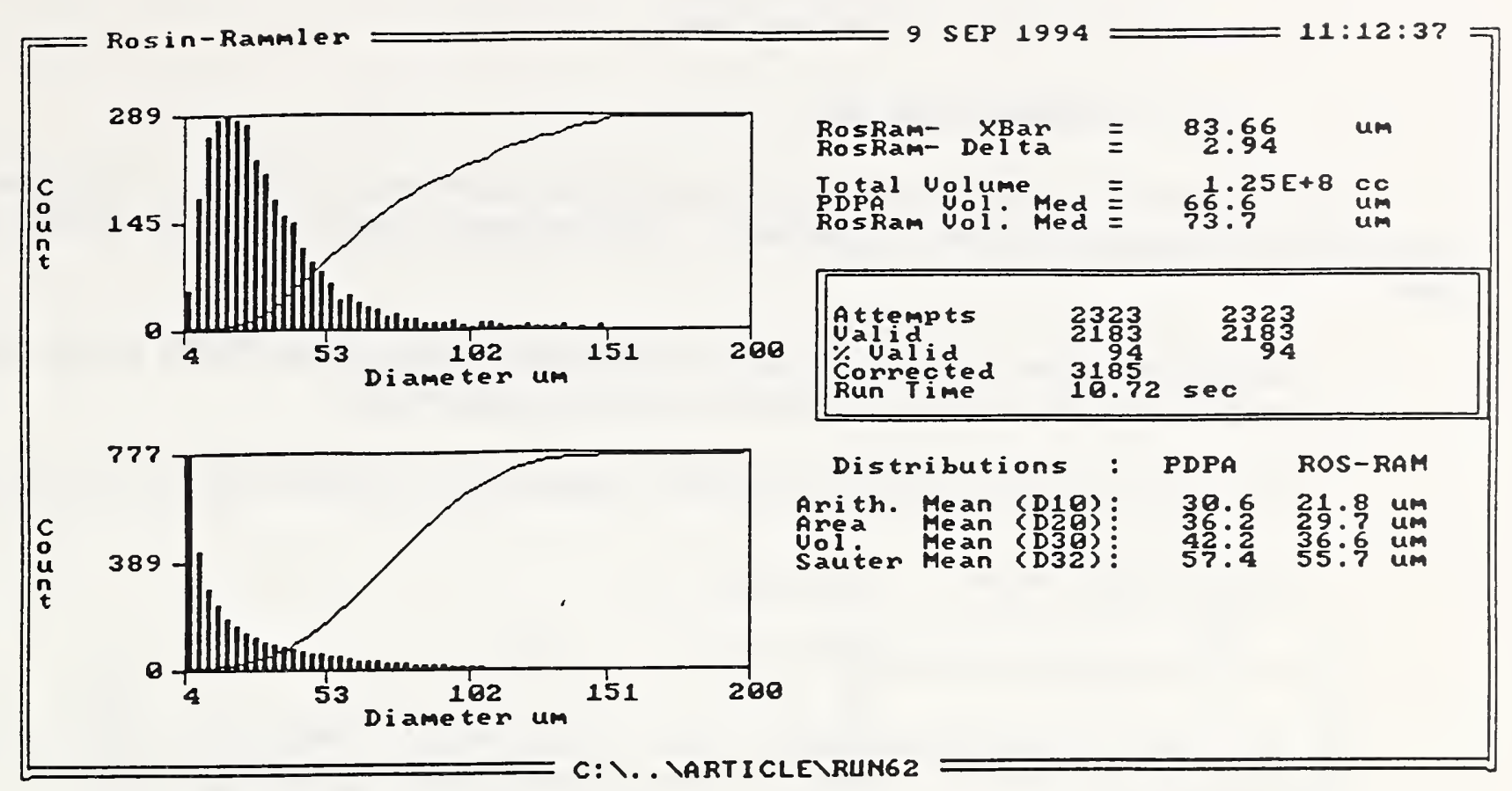

Figure 12. Analysis screen showing Best Fit Rosin-Rammler distributions.

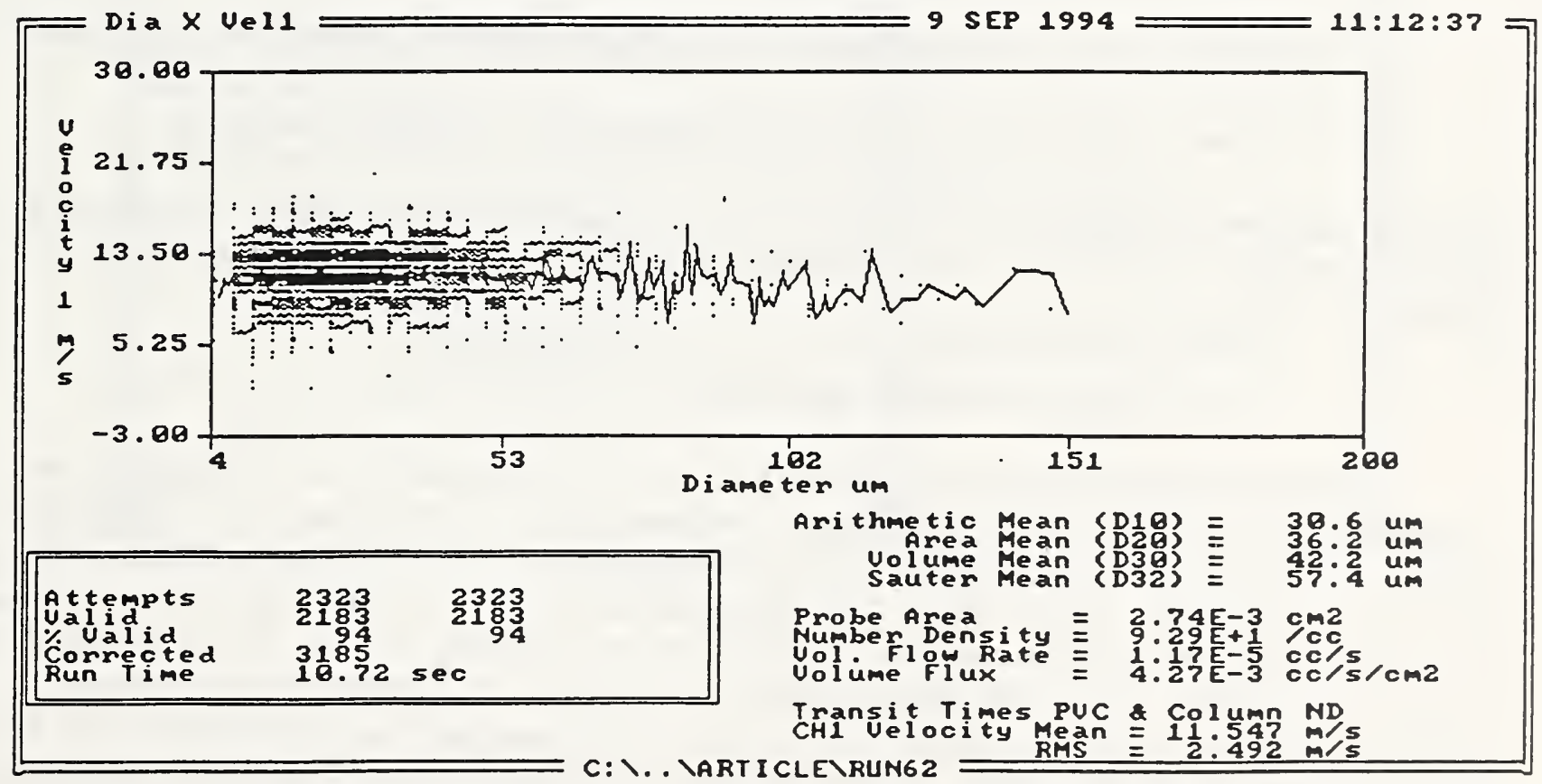

Figure 13. Analysis screen showing Diameter versus Velocity 1 correlation. 


\subsection{Operating procedures and data acquisition}

\subsubsection{Unobstructed fire tests}

For the unobstructed fire tests, the sample was a $200 \mathrm{~mm}$ square piece of PMMA. The test fixture shown in Fig. 14 was used for this set of experiments. The procedure for each test involved the following steps:

1. Adjust test fixture (without sample) to position the center of the PMMA sample at the prescribed radial and axial location relative to the spray nozzle outlet.

2. Fill water storage tank and set line pressure to desired value with outlet solenoid valve closed.

3. Weigh PMMA sample.

4. Turn on natural gas and ignite line burner.

5. Slip sample into holder and observe flame. When the color changes from blue to orange (indicating that the PMMA is burning) turn off natural gas and begin stopwatch.

6. Wait $10 \mathrm{~s}$, then begin water flow by opening solenoid valve.

7. Record total water flow and pressure.

8. Note when flame is extinguished. If it takes longer than $60 \mathrm{~s}$, record as "no suppression".

9. Close water outlet solenoid valve and extinguish flame manually if necessary.

The final step was to weigh the dried suppressed sample and record information on a test data sheet similar to the one shown in Fig. 15. Most tests were replicated three times at each location and water pressure.

\subsubsection{Generic electronics cabinet tests}

The operating procedures for the cabinet fires are similar to those for the unobstructed fires. The vertical aluminum plates, described in section 2.1, are spaced either 25 or $50 \mathrm{~mm}$ apart. The cooling fans are either set to blow upward, downward, or off. The geometry of the top surface is selected ( $80 \%$ open square grid or $40 \%$ open circular grid). Once the geometric options are chosen, the cabinet is placed in the spray chamber at the desired location relative to the water nozzle. The line burner is ignited using the spark mechanism. Since the PMMA plate is in place prior to ignition of the gas flame, proper alignment of the burner must be assured ahead of time. The system takes background data for 25 seconds and then actuates the fans (if used). Five seconds later the solenoid is actuated and water sprays into the chamber. As in the unobstructed fires, the water mist lasts 60 seconds before being shut off. At this time, the exhaust fan to the enclosure is opened and any residual flaming or smoldering is suppressed. The information on water flow rate, vessel and nozzle pressure, temperature, and suppression time is recorded and logged. The line burner is then cleaned and the cabinet is dried in preparation for the next test. Three replicate runs are made for most of the test conditions. 


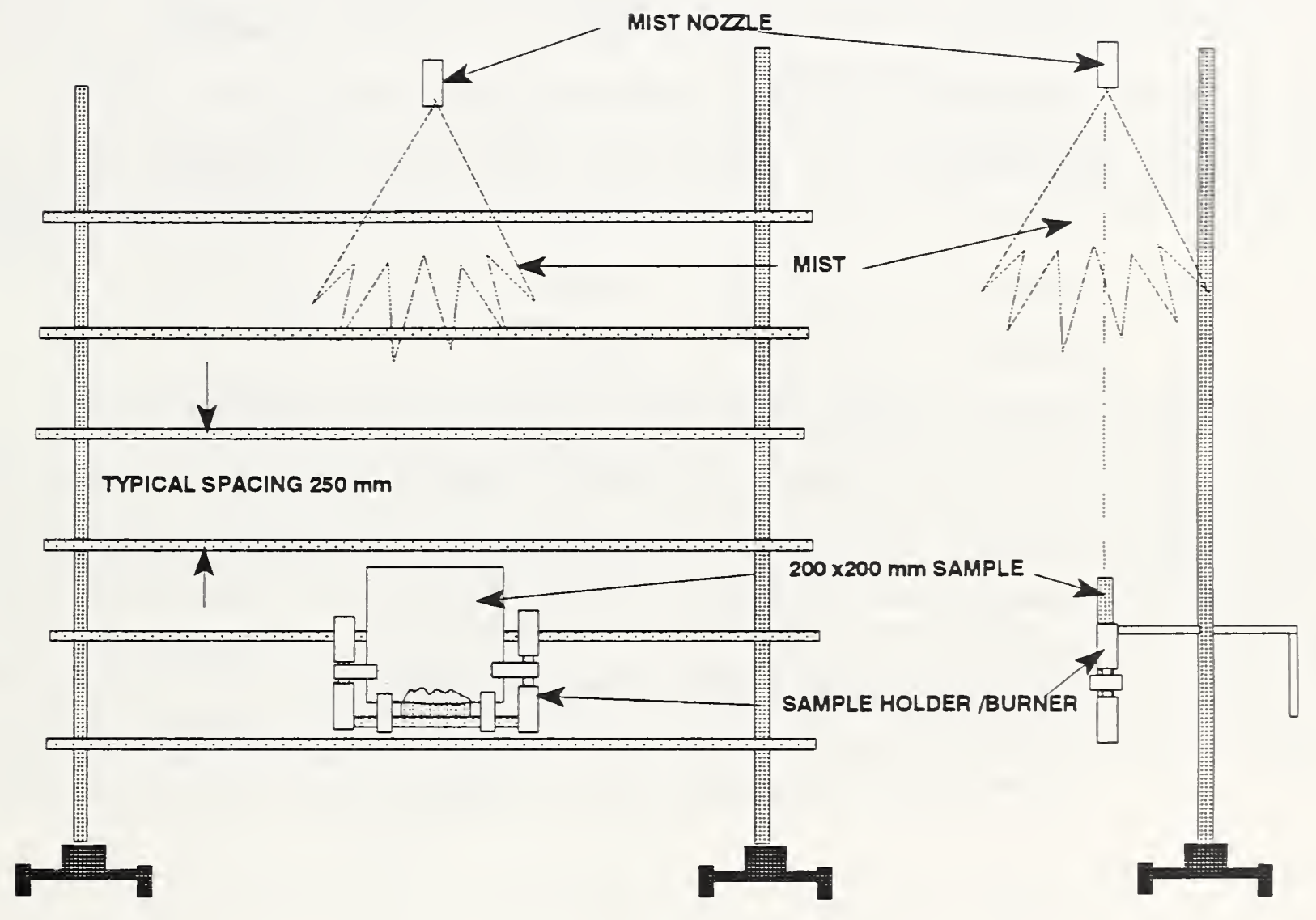

Figure 14. Schematic of test fixture used to position free-burning PMMA sample 
Date:

SAMPLE INFORMATION

Size: $200 \mathrm{~mm} \times 200 \mathrm{~mm} \times 6 \mathrm{~mm}$ (PMMA)

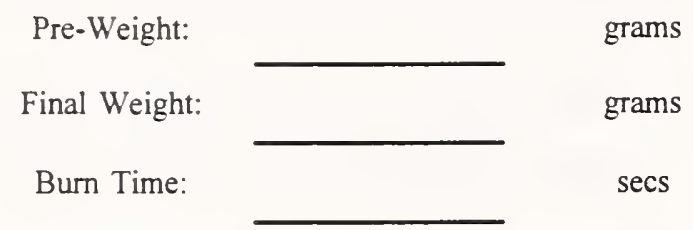

TEST RESULTS

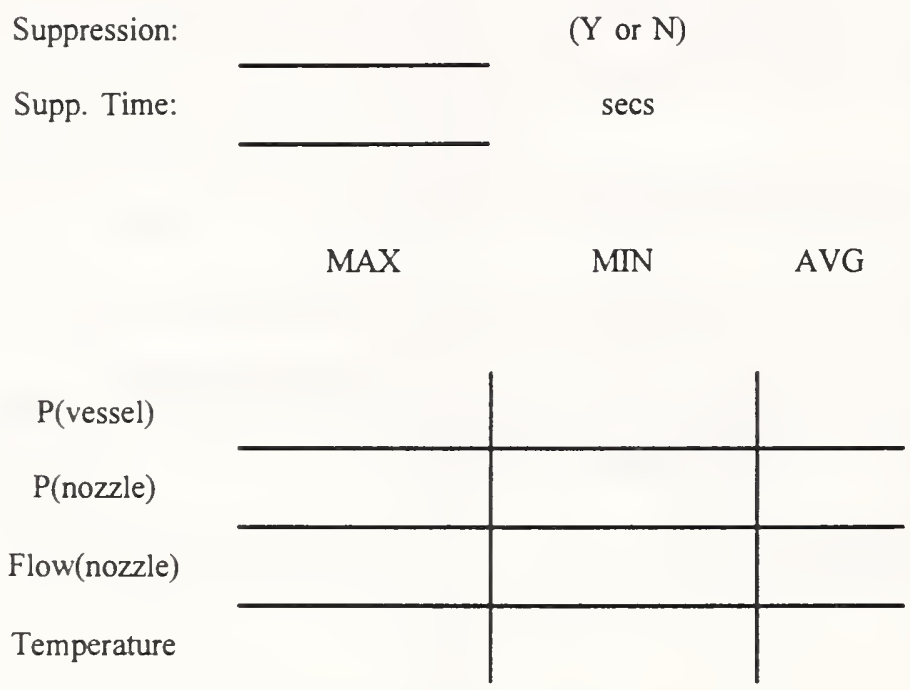

Sample Location:

Init. $\mathrm{H} 2 \mathrm{O}$ Pressure:

Nozzle Type:

Data Filename:

$\mathrm{kPa}$

$\mathrm{kPa}$

$\mathrm{L} / \mathrm{min}$

${ }^{\circ} \mathrm{C}$

Figure 15. Sample data sheet for unobstructed fire tests 


\subsubsection{Phase-Doppler particle analyzer}

A schematic of the PDPA and its location in the test enclosure are shown in Fig. 16. The procedure for using the analyzer consists of alignment of laser beams, receiver/transmitter optics, and selection of proper PMT high voltage. The alignment procedure is performed on a daily basis. Critical elements of alignment such as beam intensity and proper focus within receiver optics are checked. Laser beam intensity is checked using a laser power meter. Beam intensity measurements are made to insure that coupling efficiency into the fiber optic cables is at least $50 \%$. Small adjustments of the optical couplers are made at this point to maximize intensity. Proper operation of the system was checked using a small water spray nozzle. After alignment, the PMT high voltage setting is selected for each water mist spray condition. Within the DSA software, there is a routine that automatically determines the optimum PMT high voltage. Three iterations of 1500 samples are performed for each different spray condition. Using statistical methods, the instrument determines what the high voltage should be and sets this value (Aerometrics, 1993b). The value for the PMT high voltage is then used for each test having the same spray condition.

Once the test area has been prepared, the system is placed in a standby mode. Data are collected upon the release of water mist from the nozzle. In many cases, to avoid the short period after the initial burst of water, a delay time is allowed before data collection. By delaying the start of data collection, velocity averages are more precise. Once the data are saved, they can be post-processed with all test variables and functions.

\subsubsection{Data acquisition system}

The data acquisition system consists of a control unit, a voltmeter, and portable computer. The control unit has an electrically guarded analog input card where the output of all instruments are connected and a relay actuator card which is used to drive a series of solid state AC relays to control fans and electronic valves. The voltmeter recognizes when an analog channel is closed and sequentially takes a voltage reading and sends the result to the computer. The data system is controlled through in-house software. The collection routine reads an input file to get channel numbers, channel descriptions, and calibration constants. During the test, the data are saved to the hard drive and relay actuator channels are turned on and off at the pre-set time. Also, the display screen indicates values of channels being measured, time elapsed, and status of relay channels. Minimum, maximum, and average values of all channels collected are displayed at the end of a collection run. The data file structure is ASCII format and may be read into a variety of plotting and reduction programs available. 


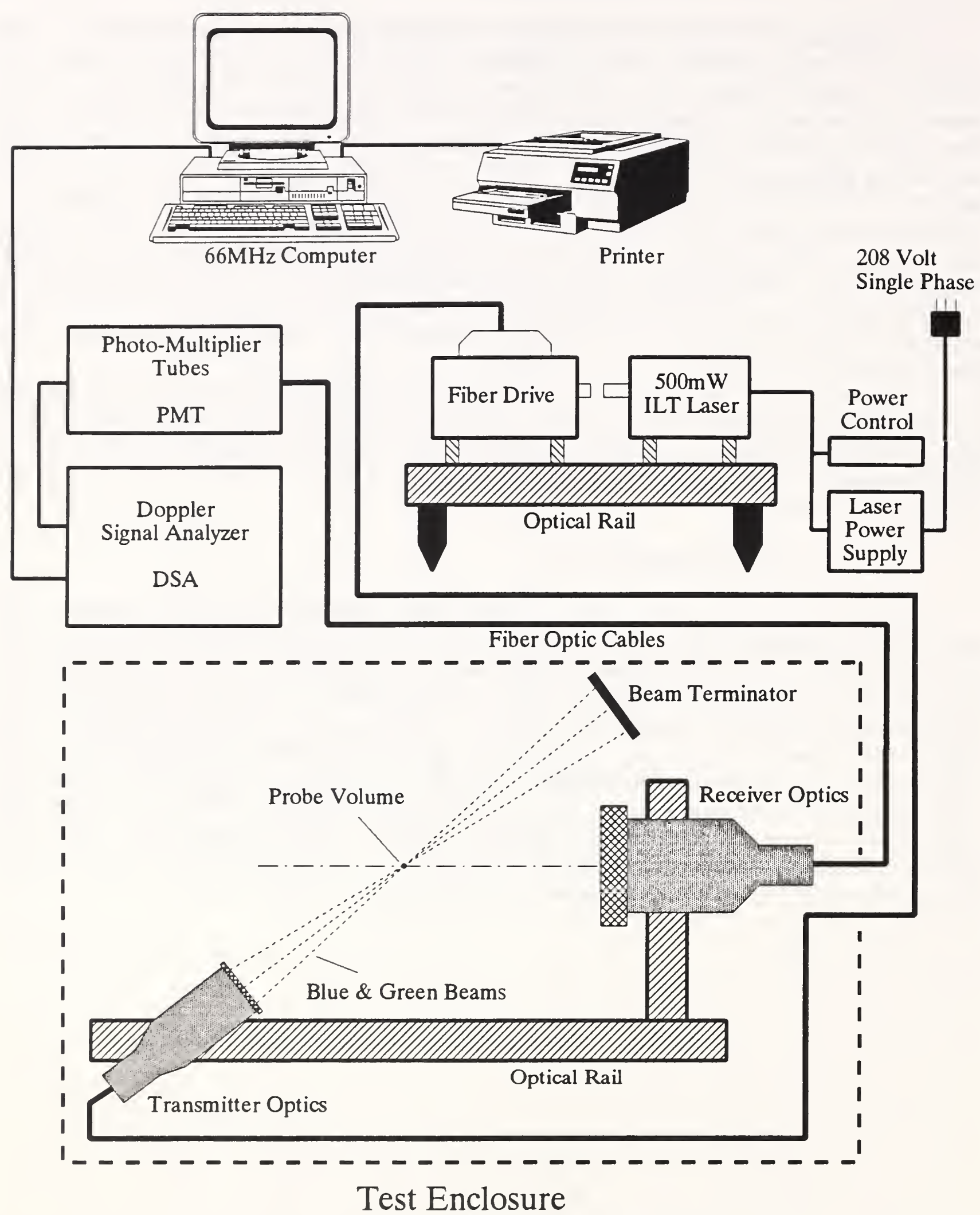

Figure 16. Schematic of phase-Doppler particle analyzer used for velocity and size measurements 


\section{Experimental Results}

\subsection{Test Matrix}

The main dependent variables measured in this study were the time required to suppress the fire, the total water flow, the droplet size distribution, and the droplet velocities. The controlled independent parameters were the nozzle design, water pressure, location relative to the nozzle, and configuration of the test article. Additional experiments were conducted using a second fluid, $\mathrm{CF}_{3} \mathrm{H}$, to compare the performance of a water spray to a gaseous agent. Table 2 lists all the parameters, their ranges, and methods of measurement.

Table 2. Parameters examined and measurement techniques

\begin{tabular}{|c|c|c|c|}
\hline Parameter & $\begin{array}{l}\text { Dependent or } \\
\text { Independent }\end{array}$ & Range & $\begin{array}{l}\text { Measurement } \\
\text { Method }\end{array}$ \\
\hline $\begin{array}{l}\text { time to } \\
\text { extinguishment }\end{array}$ & dependent & 0 to $>60 \mathrm{~s}$ & stopwatch \\
\hline total water flow & dependent & 0 to $10 \mathrm{l} / \mathrm{min}$ & turbine meter \\
\hline droplet size & dependent & 4 to $150 \mu \mathrm{m}$ & PDPA \\
\hline $\begin{array}{l}\text { droplet speed (axial } \\
\text { and cross-stream } \\
\text { directions) }\end{array}$ & dependent & 0 to $30 \mathrm{~m} / \mathrm{s}$ & PDPA \\
\hline fluid & independent & liquid water and gaseous $\mathrm{CF}_{3} \mathrm{H}$ & initial config. \\
\hline nozzle & independent & pressure-jet and air-atomized & initial config. \\
\hline water pressure & independent & 0.32 to $5.5 \mathrm{MPa}$ & transducer \\
\hline air pressure & independent & 0.40 to $0.46 \mathrm{MPa}$ & transducer \\
\hline $\mathrm{CF}_{3} \mathrm{H}$ pressure & independent & 3.0 to $4.0 \mathrm{MPa}$ & transducer \\
\hline $\begin{array}{l}\text { distance from nozzle } \\
\text { centerline }\end{array}$ & independent & $0, \pm 0.5, \pm 1.0 \mathrm{~m}$ & scale \\
\hline $\begin{array}{l}\text { distance below } \\
\text { nozzle }\end{array}$ & independent & $0.25,0.50,0.75,1.00,1.25,1.50 \mathrm{~m}$ & scale \\
\hline test article & independent & $\begin{array}{l}\text { none, unobstructed, mock computer } \\
\text { cabinet }\end{array}$ & initial config. \\
\hline $\begin{array}{l}\text { mock cabinet top } \\
\text { opening }\end{array}$ & independent & $100 \%, 80 \%, 40 \%, 0 \%$ & scale \\
\hline fan airflow direction & independent & up, down, off & switch \\
\hline plate spacing & independent & 25 and $50 \mathrm{~mm}$ & initial config. \\
\hline
\end{tabular}




\subsection{Flow Characteristics with No Test Article Present}

\subsubsection{Pressure-jet nozzles}

Total water flow versus pressure measurements were taken with no test article present in the enclosure using the low (PJ-L) and high (PJ-H) capacity pressure-jet nozzles. The flow increased with pressure as can be seen in Fig. 17. Also plotted in the figure are the stream-wise $\left(\mathrm{V}_{1}\right)$ and cross-stream $\left(V_{2}\right)$ velocities and the Sauter-mean diameters for the two different size nozzles. (Note: The velocity and SMD measured at the highest pressure, indicated by the cross-hatched regions of Fig. 17, are for a point $0.82 \mathrm{~m}$ below the nozzle, while the other data correspond to a centerline position $1.0 \mathrm{~m}$ below the nozzle.) The data were collected with the PDPA for the first 30 seconds after the flow was initiated and for the second 30 seconds after initiation to determine how steady the conditions were. In all cases the initial pulse of pressure was greater than the reported steady state (taken after the 60 second run), which lead to higher initial velocities and larger measured droplet sizes. A change between the first and second 30 second periods on $\mathrm{V}_{2}$ was not observed because the absolute magnitude of the transverse velocity is small. Visual observations suggest that the major transient was over within 10 seconds but it was difficult to follow the changing conditions in this time frame because the PDPA relies on a minimum number of valid measurements (hence, measuring time) to be statistically meaningful.

The initial low pressure data were collected with the photomultiplier tube (PMT) voltage fixed at $350 \mathrm{~V}$, while the voltage for the $5.5 \mathrm{MPa}$ condition was chosen automatically by the system to give the optimum signal. The automatic setting resulted in voltages higher than $350 \mathrm{~V}$, which increased the sensitivity of the PMT to weaker scattering signals from smaller particles. Thus, the lower pressure data are biased towards larger particles and the higher pressure data are biased towards a smaller SMD. The velocities also become biased, respectively, towards the small and large particles. Because the measuring location was closer to the nozzle outlet at the highest pressure setting, the velocity naturally would be expected to be higher, which is the case with the velocity data in the cross-hatched region of Fig. 17. It is unknown how much effect the higher PMT voltage had on these data. From Fig. 13, however, one can observe a slightly negative trend between increasing droplet diameter and axial velocity.

\subsubsection{Air-atomized nozzles}

Two air-atomized nozzles were examined in this study, one rated at $3 \mathrm{l} / \mathrm{min}$ flow (AA-L) and the second at $10 \mathrm{l} / \mathrm{min}(\mathrm{AA}-\mathrm{H})$. The total water flow from the larger nozzle was more than the spray enclosure could handle without significant splashing from the walls. No attempt was made to optimize the water spray for the enclosure and type of fire targeted in this study. A single water and air pressure were selected based upon the following manufacturer's suggested values:

\begin{tabular}{|c|c|c|c|}
\hline Nozzle & Atomizing Air Pressure & Water Pressure & Water Flow \\
\hline AA-H & $460 \mathrm{kPag}$ & $364 \mathrm{kPag}$ & $9 . \overline{1 \pm 1.0 \mathrm{l} / \mathrm{min}}$ \\
\hline AA-L & $400 \mathrm{kPag}$ & $320 \mathrm{kPag}$ & $2.8 \pm 0.4 \mathrm{l} / \mathrm{min}$ \\
\hline
\end{tabular}

Droplet size and velocity measurements were not made in the air-atomized spray. From visual observations one could identify three distinct jets along a single plane, with the total cone angle between the outermost jets considerably wider than observed with the pressure-jet nozzle.

\subsubsection{Gaseous agent nozzle}

A gaseous agent was selected as a benchmark against which the performance of the water spray 


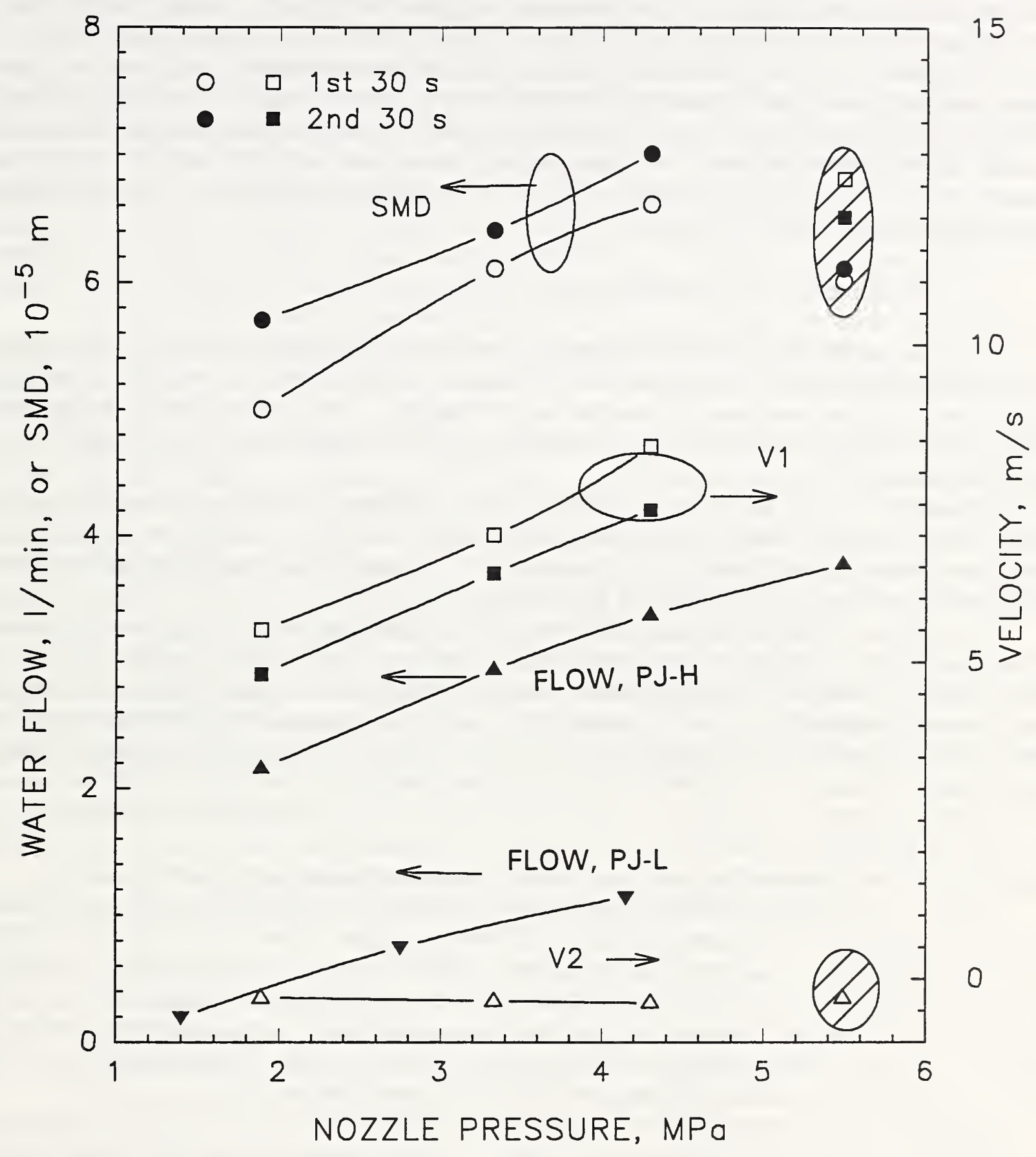

Figure 17. Water flow as a function of pressure measured for pressure-jet nozzles. Droplet size and velocity measured with PJ-H nozzle on centerline, $1.0 \mathrm{~m}$ downstream, except for the 5.5 MPa case, taken $0.82 \mathrm{~m}$ downstream, and shown in cross-hatched region. The PMT voltage was increased for these latter measurements. 
could be compared. Rather than halon 1301 , which a water spray system could conceivably replace, a halon alternative, $\mathrm{CF}_{3} \mathrm{H}$, was chosen because it has been approved by the EPA for normally occupied spaces (EPA, 1993). Trifluoromethane $\left(\mathrm{CF}_{3} \mathrm{H}\right)$, also referred to as HFC-23 or FE-23, is known to be much less effective than the halon. It has a molecular weight of $70 \mathrm{~kg} / \mathrm{kmol}$, a normal boiling point of $-82{ }^{\circ} \mathrm{C}$, a vapor pressure at $20^{\circ} \mathrm{C}$ of $4.69 \mathrm{MPa}$, and density at these conditions of $0.685 \mathrm{~kg} / \mathrm{m}^{3}$.

The agent entered the distribution system as a gas and flooded the entire enclosure as it was released. A multiple-nozzle body with the pressure-jet water nozzles, themselves, removed was used to discharge the gas outward into six equally divided segments. The agent was discharged from above in the center of the enclosure with no restrictions between the storage bottle valve and the nozzle body. Even so, the flow was limited by the bottle outlet valve, resulting in a release more prolonged than the $10 \mathrm{~s}$ recommended by NFPA 2001 (1994).

\subsection{Unobstructed Fire Experiments}

The $200 \mathrm{~mm}$ square plate PMMA sample shown at the top of Fig. 2 was placed into the spray chamber at different positions to determine where the water spray was sufficient in strength to extinguish a burning solid that was completely exposed to the environment. The sample holder and igniter were located on the test stand as shown in Fig. 14 and the procedure outlined in section 2.4.1 was followed for each experiment.

The sample burned easily after the initial $10 \mathrm{~s}$ period. When the flames were allowed to continue unabated the plate began to warp and the lower portion melted and dripped around the gas supply tube. The average mass consumed during a $10 \mathrm{~s}$ pre-burn and the next $60 \mathrm{~s}$ was between 3 and $4 \mathrm{~g}$, which translates to an average heat release rate of approximately $1.5 \mathrm{~kW}$.

The regions in which the unobstructed fire could be extinguished using the high flow PJ-H nozzle are shown in Fig. 18. Each square represents a different measurement location, with the cross-hatched squares identifying locations where suppression occurred within a minute, black indicating that the fire was unsuppressed within $60 \mathrm{~s}$, and white indicating the sample was outside of the field of the spray. Four different nozzle pressures were investigated: $1.4,2.7,4.1$, and $5.5 \mathrm{MPag}$. The penetration into the chamber was very limited at $1.4 \mathrm{MPag}$, but the spray pretty much filled the chamber when the pressure was 2.7 MPag or higher. The number of locations with successful suppression increased from one near the nozzle for the lowest pressure to 15 at $2.7 \mathrm{MPag}$. Increasing the pressure to 4.1 or $5.5 \mathrm{MPag}$ enhanced by two the number of points where the fire could be extinguished within 60 seconds.

Figures 19 through 22 are three dimensional plots of the time to extinction versus position within the chamber using the PJ-H pressure-jet nozzle at different pressures. When the pressure is $2.1 \mathrm{MPag}$, the time to extinction increases sharply as the fire moves off the centerline. At the furthest point below the nozzle $(1.5 \mathrm{~m})$, the fire cannot be extinguished even on the centerline $(0 \mathrm{~m})$. Figures 20,21 and 22 show the impact of increasing the pressure on the time to extinction. A pressure of 4.1 MPag was sufficient to suppress a flame anywhere within the spray cone all the way to the lowest portion of the chamber. A further increase to 5.5 MPag showed only marginal improvement.

Figures 23 to 25 are profiles of the time required for flame extinction along the centerline, and as a function of distance from the centerline 0.5 and $1.0 \mathrm{~m}$ downstream. In the two highest pressure experiments, Fig. 23 shows the fire going out in less than $5 \mathrm{~s}$ at all locations on the centerline. The radial profiles shown in Figs. 24 and 25 are similar to each other in shape, indicating that between 0.5 and $1.0 \mathrm{~m}$ below the nozzle the flow field changes are not great. The exception is for the $1.4 \mathrm{MPag}$ condition, which is just barely enough to extinguish the flame $0.5 \mathrm{~m}$ below the nozzle, but insufficient at $1.0 \mathrm{~m}$.

The lower flow rate (PJ-L) pressure-jet nozzle has a narrower spray cone angle. This can be seen by comparing the plot of the time to extinction for the PJ-L operating at $4.1 \mathrm{MPag}$ (Fig. 26) to a plot of 
the similar condition using the PJ-H nozzle (Fig. 22). Along the centerline the two nozzles are equally effective, up to the maximum distance measured downstream, where, as shown in Fig. 27, the higher capacity nozzle puts out the fire $16 \mathrm{~s}$ faster.

Figures 28 and 29 are contour maps showing the regions in the spray in which the flaming PMMA sample can be extinguished within one minute. As the pressure is increased in the PJ-H nozzle from a minimum of $1.37 \mathrm{MPag}$ up to $4.1 \mathrm{MPag}$ (see Fig. 28) the area which is successfully protected increases significantly. Increasing the pressure further does not extend the protection. Figure 29 shows that the PJ-L is more effective than the PJ-H at $1.37 \mathrm{MPag}$; i.e., the region of successful extinguishment extends below $1.0 \mathrm{~m}$. The reverse is true when the pressure is increased to $4.1 \mathrm{MPag}$. This can be explained by the narrower spray cone angle of the PJ-L. Even though less water flows through the nozzle, the mass flux along the centerline may be higher for the PJ-L than for the PJ-H. At greater pressures the higher total flow of water through the PJ-H is sufficient to penetrate effectively to the bottom of the test chamber; hence, the broader the region protected.

The air-atomized nozzles were less effective than the pressure-jet nozzles for the same water delivery rate. This is due to the vastly different spray patterns from the Securiplex systems, which cover a much broader area. Since the fire is localized, the advantage of the air-atomized design was not exploited in our testing.

Figure 30 shows the regions in which the vertical PMMA plate was extinguished within $60 \mathrm{~s}$ after ignition using the larger air-atomized (AA-H) nozzle. The impact of the multiple lobes on the regions in the chamber which could be extinguished is evident. There are two islands on either side of the centerline between 0.25 and $0.50 \mathrm{~m}$ below the exit where the flame is not suppressed (N.S.). Further down in the chamber the central stream can be seen to penetrate to the bottom, with the two side lobes unable to suppress the fire below about $0.9 \mathrm{~m}$. Figure 31 is a plot of the actual time to extinction as a function of position. The complex spray pattern is evident here as well.

The smaller air-atomized nozzle, AA-L, behaved similarly. Along the centerline the water spray was very effective, instantly extinguishing the flame. At the $1.5 \mathrm{~m}$ downstream location the smaller nozzle took about $10 \mathrm{~s}$ less than the larger nozzle. Off axis, however, the AA-L nozzle was unable to extinguish the flame in under $60 \mathrm{~s}$ at any location equal to or greater than $0.5 \mathrm{~m}$ below the nozzle tip.

\subsection{Obstructed Fires}

The operating procedures for experiments involving the mock computer cabinet were similar to the unobstructed experiments with the following noteworthy modifications:

- The configuration of the test article (top condition, plate spacing, and fan operation) had to be adjusted before beginning each test.

- The PMMA sample was in place at the time the gas burner was ignited. The initial condition for the test (the first appearance of a yellow flame) remained the same.

- The pre-burn time was increased to $30 \mathrm{~s}$ to ensure a robust fire.

\subsubsection{Experimental matrix}

Experiments with the obstructed fires were confined to water sprays using only the high flow pressure-jet nozzle $(\mathrm{PJ}-\mathrm{H})$ and gaseous discharges using $\mathrm{CF}_{3} \mathrm{H}$. Table $3 \mathrm{a}$ and $3 \mathrm{~b}$ list the parametric variations investigated. Three replicates of each condition were conducted. The first 31 configurations listed in Table $3 a$ used water (indicated by a "w"); the remaining eight (Table $3 b$ ) were with gaseous $\mathrm{CF}_{3} \mathrm{H}$ (indicated by " $\mathrm{g}$ "). The horizontal distance from the nozzle centerline to the center of the PMMA plate is designated $\mathrm{Y}$, and the distance below the nozzle to center of the PMMA plate is $\mathrm{X}$. The 


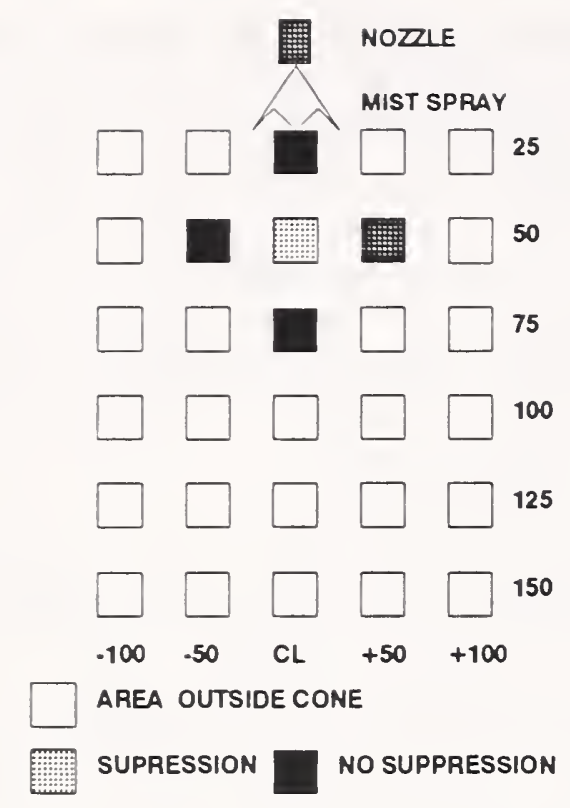

1.4 $\mathrm{MPa}$

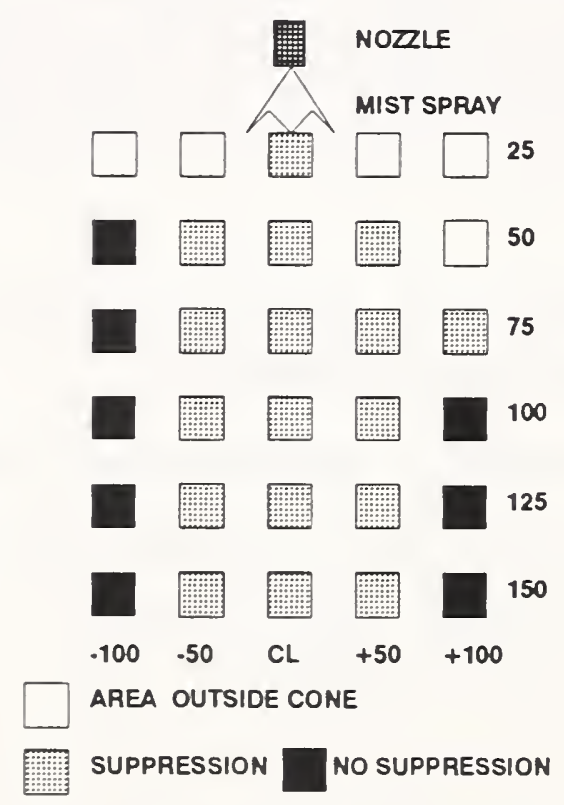

4.1 $\mathrm{MPa}$

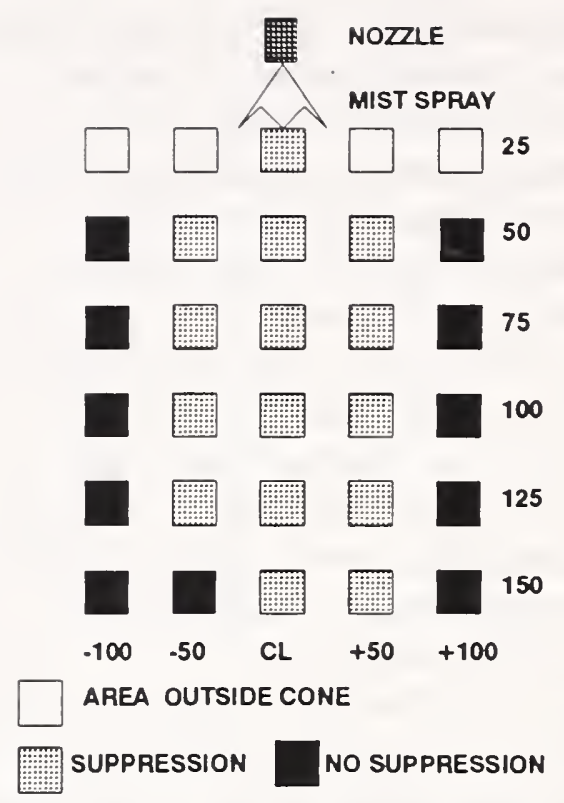

2.7 $\mathrm{MPa}$

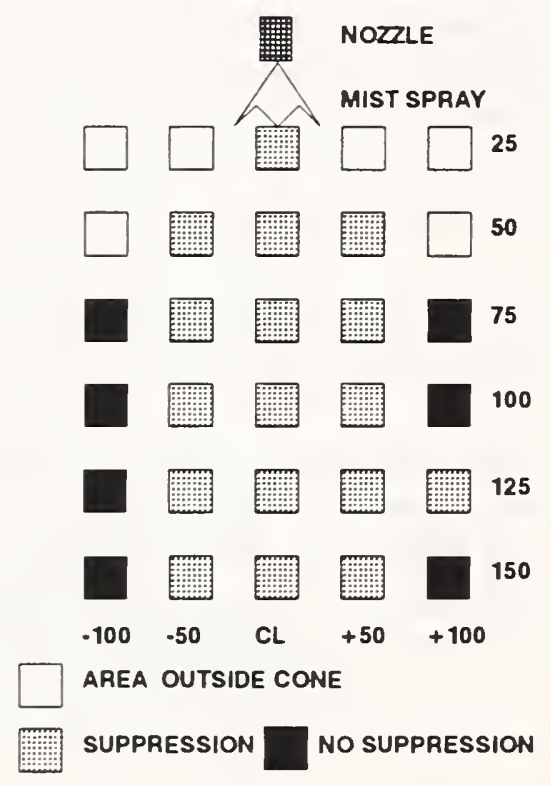

5.5 MPa

Figure 18. Summary of regions where unobstructed fires were suppressed by water spray 


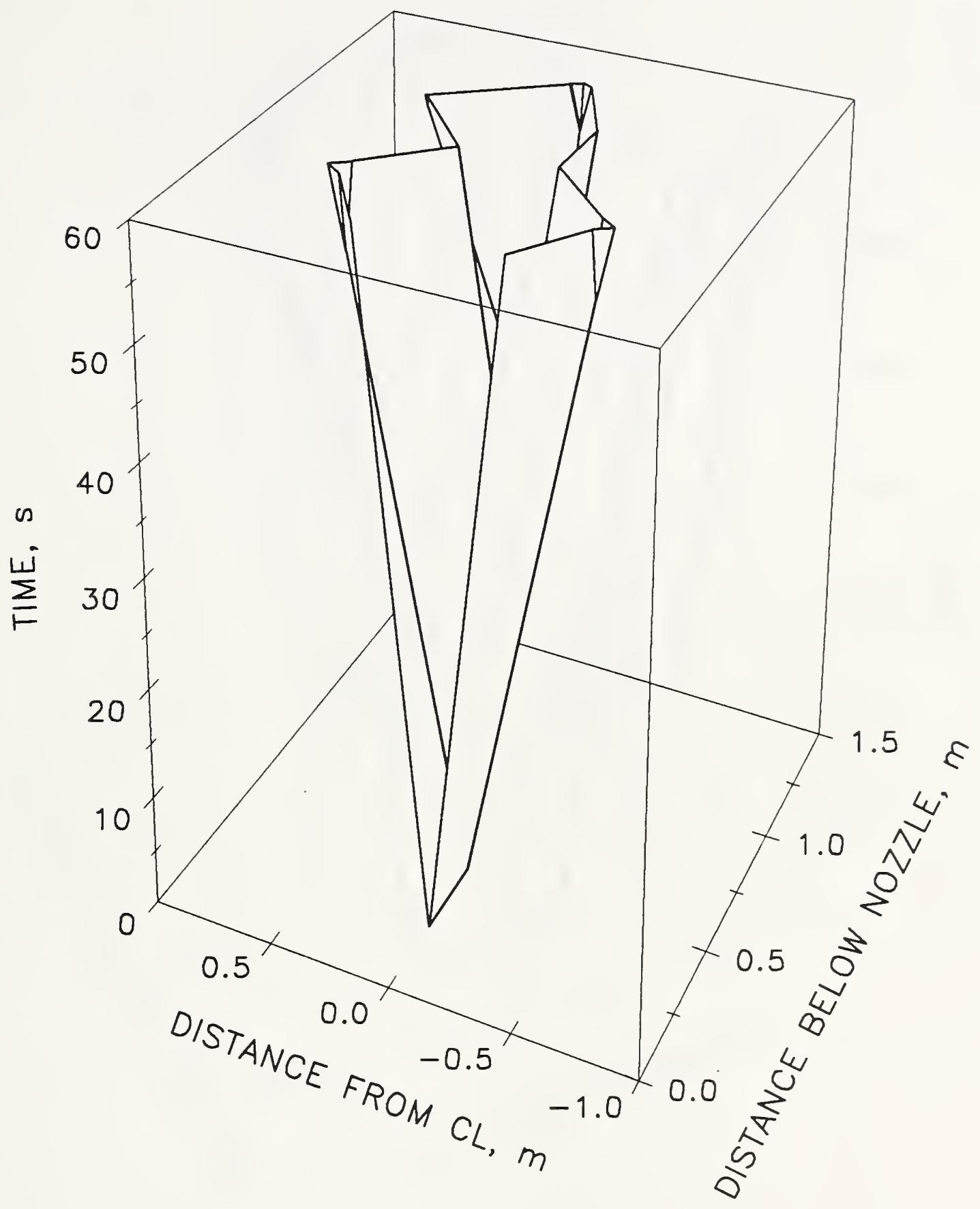

Figure 19. Time to extinction of flame as a function of position below PJ-H nozzle. Pressure is $2.06 \mathrm{MPag}$. 


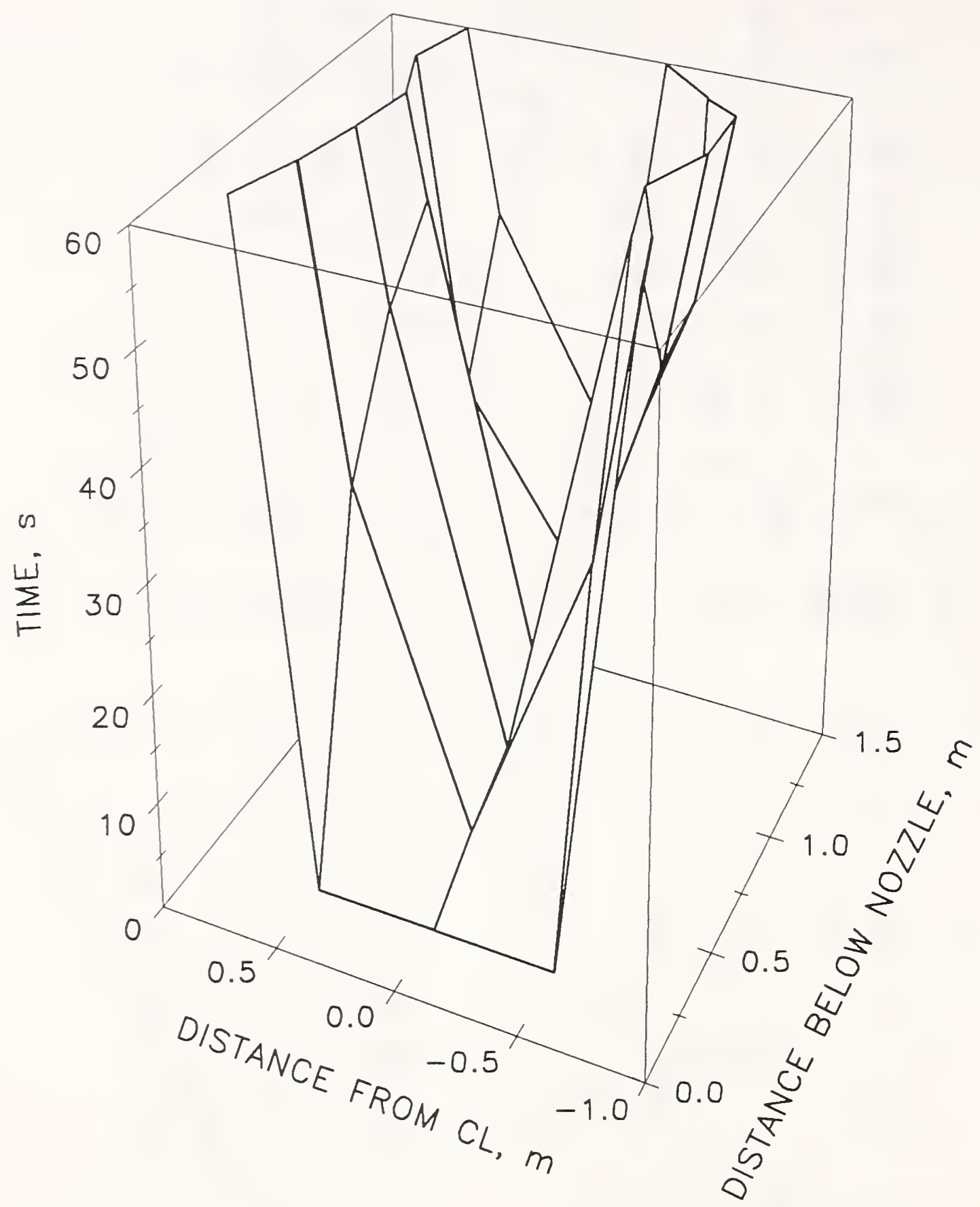

Figure 20. Time to extinction of flame as a function of position below PJ-H nozzle. Pressure is $2.75 \mathrm{MPag}$. 


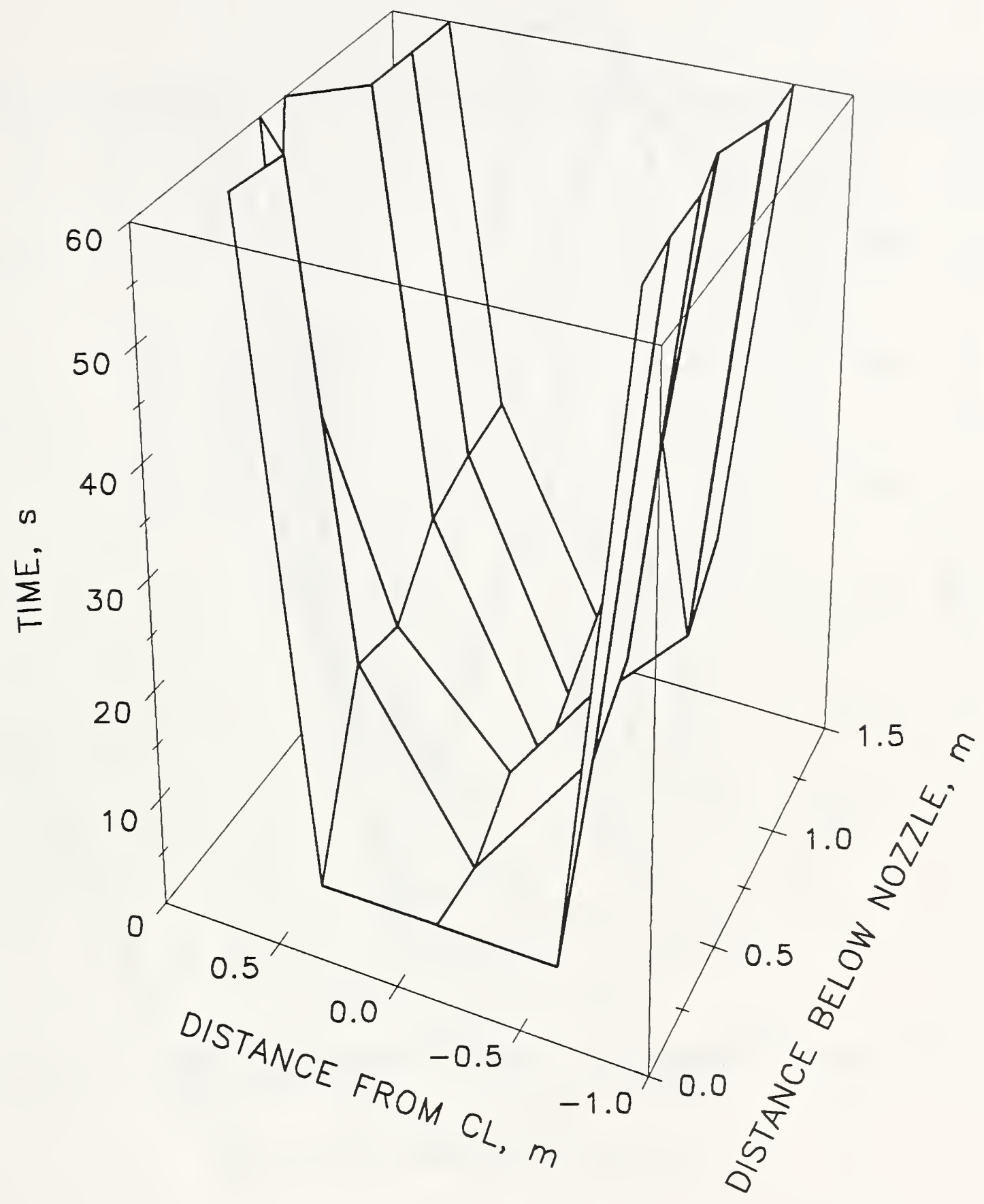

Figure 21. Time to extinction of flame as a function of position below PJ-H nozzle.

Pressure is $4.12 \mathrm{MPag}$. 


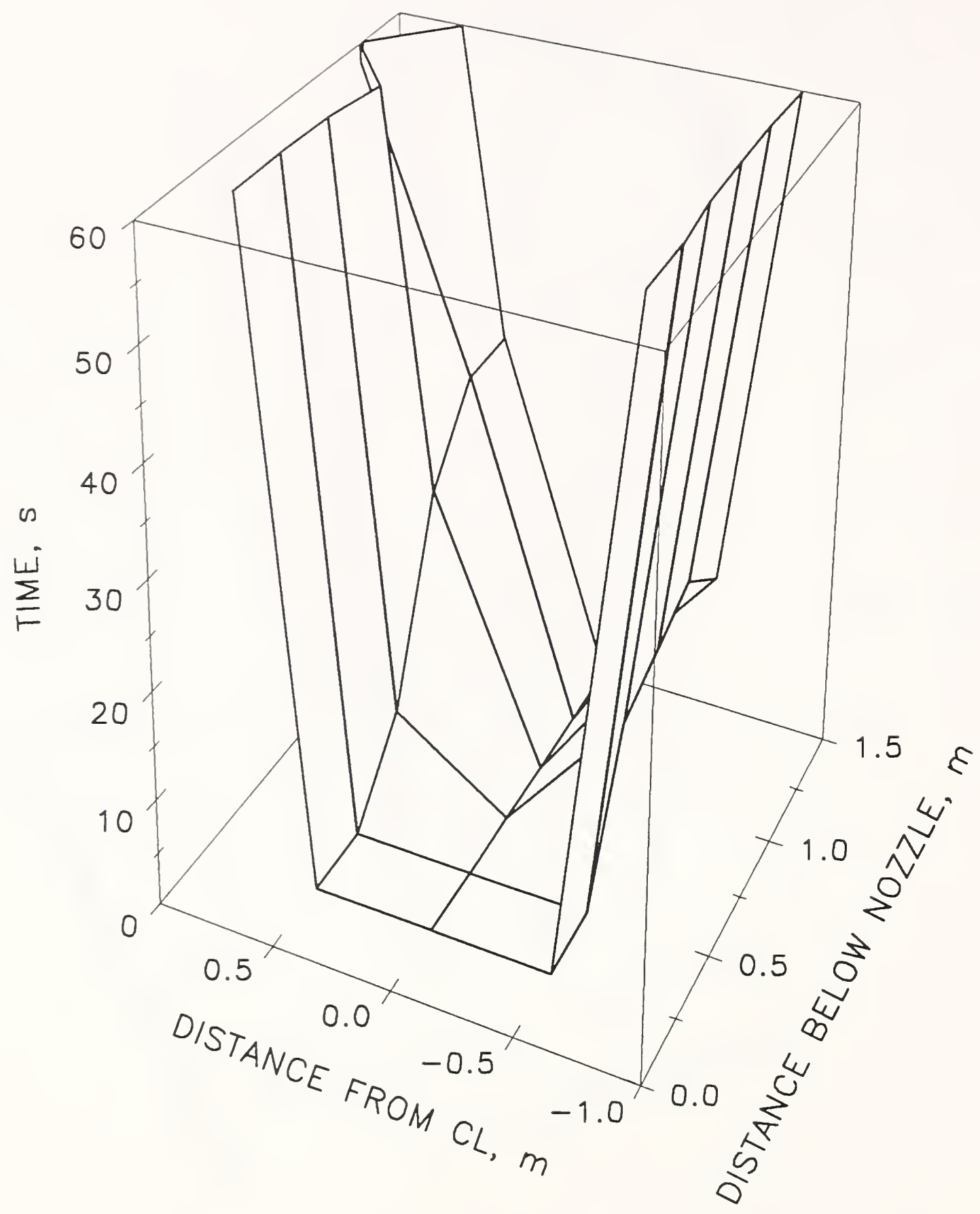

Figure 22. Time to extinction of flame as a function of position below PJ-H nozzle.

Pressure is $5.50 \mathrm{MPag}$. 


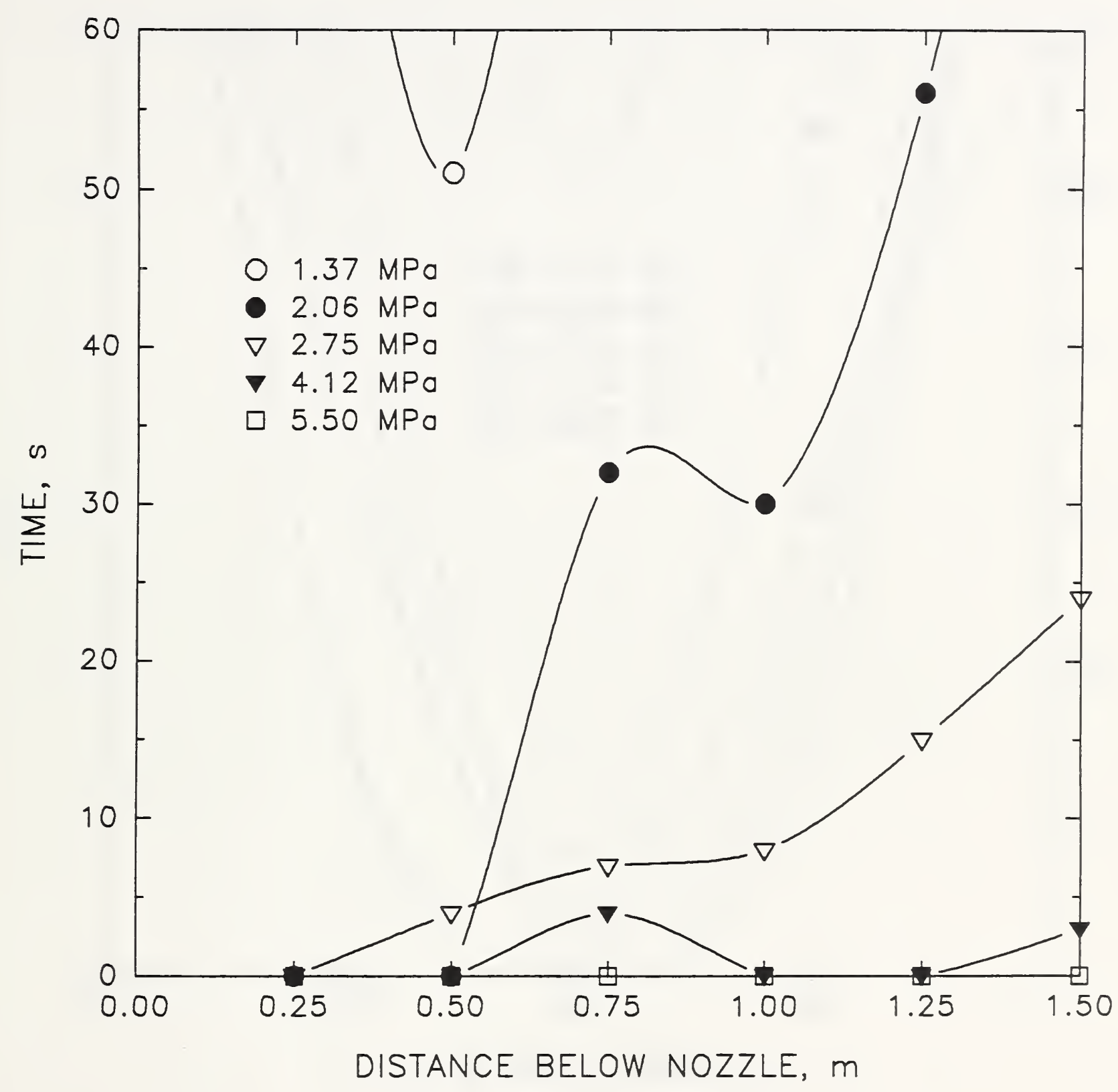

Figure 23. Time to extinction of flame using PJ-H. pressure-jet nozzle, as a function of downstream distance on centerline and different water pressures 


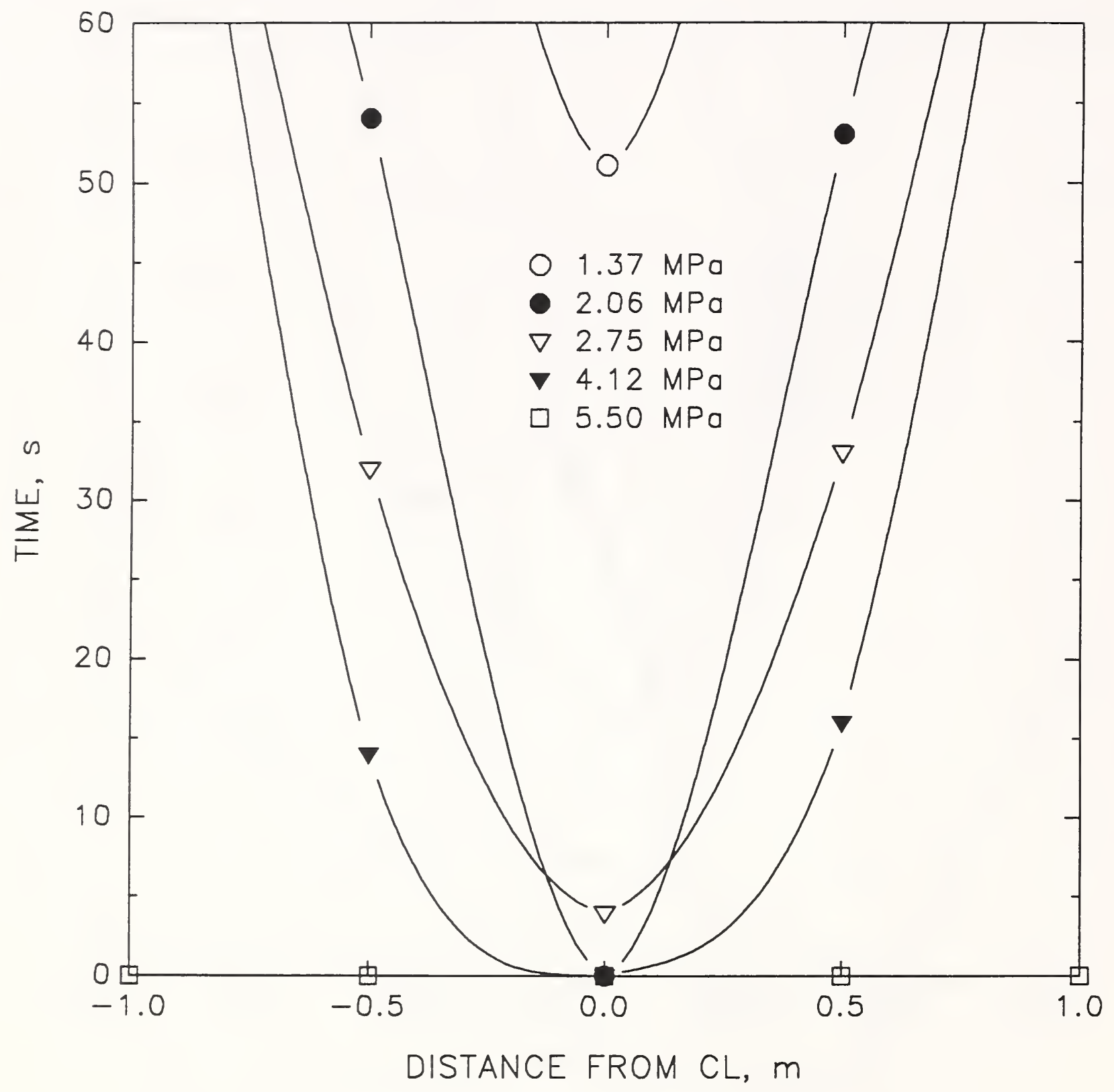

Figure 24. Time to extinction of flame using PJ-H pressure-jet nozzle, as a function of cross-stream position $0.5 \mathrm{~m}$ downstream and different water pressures 


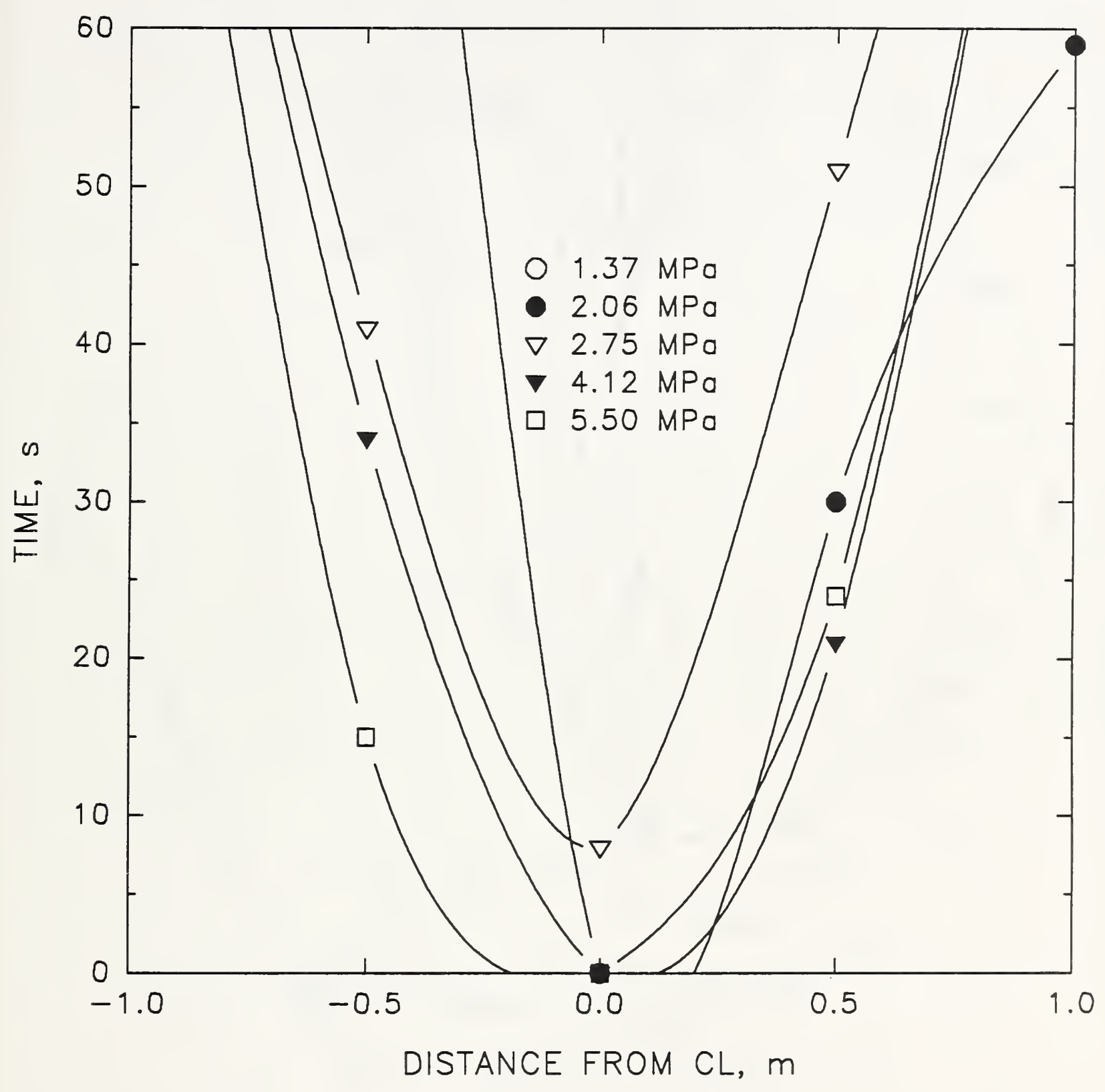

Figure 25. Time to extinction of flame using PJ-H pressure-jet nozzle, as a function of cross-stream position $1.0 \mathrm{~m}$ downstream and different water pressures 


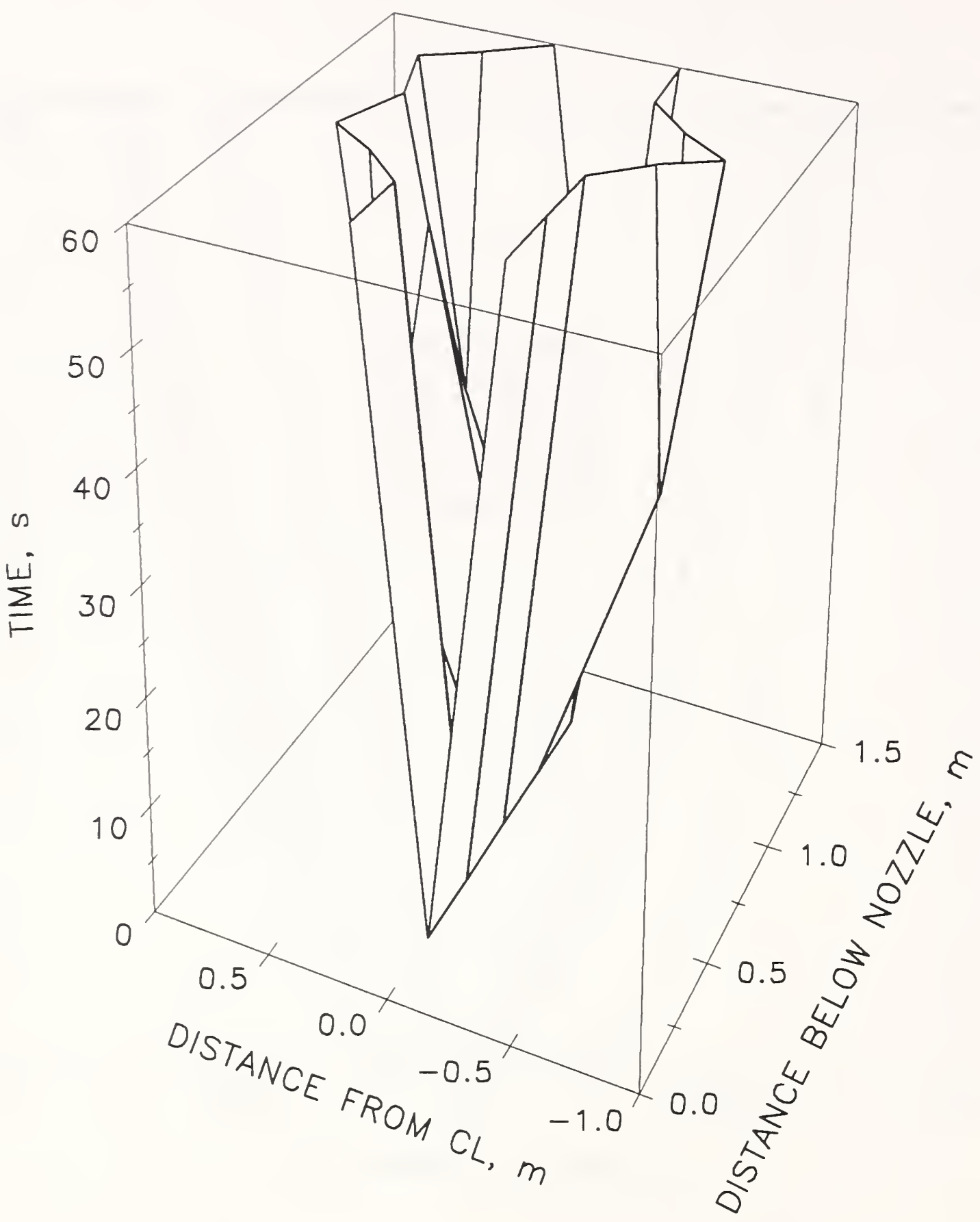

Figure 26. Time to extinction of flame using PJ-L pressure-jet nozzle at 4.12 MPag, as a function of position relative to nozzle exit. 


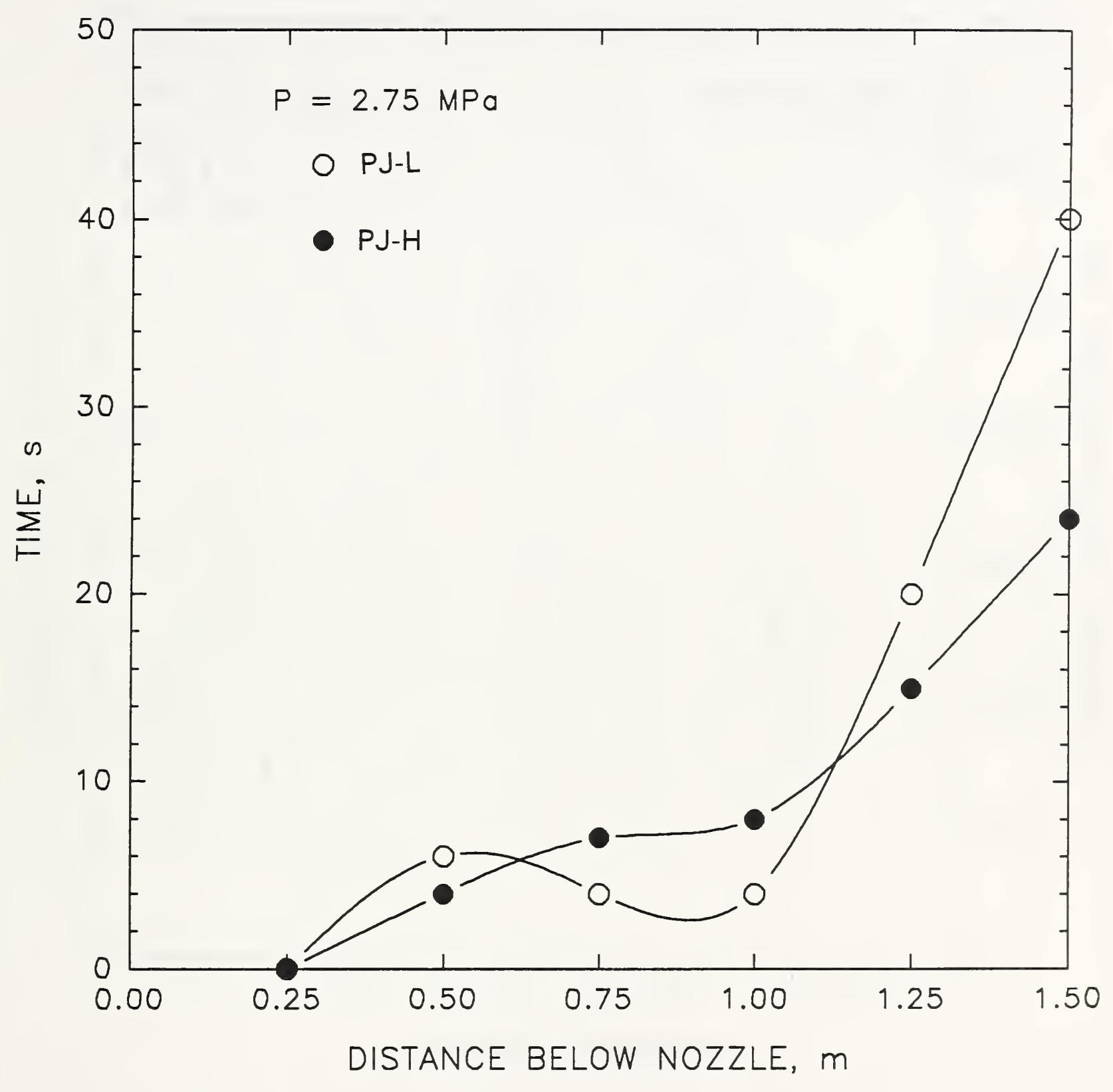

Figure 27. Time to extinction of flame comparing PJ-L and PJ-H pressure-jet nozzles at 2.74 MPag, as a function of downstream distance on centerline 


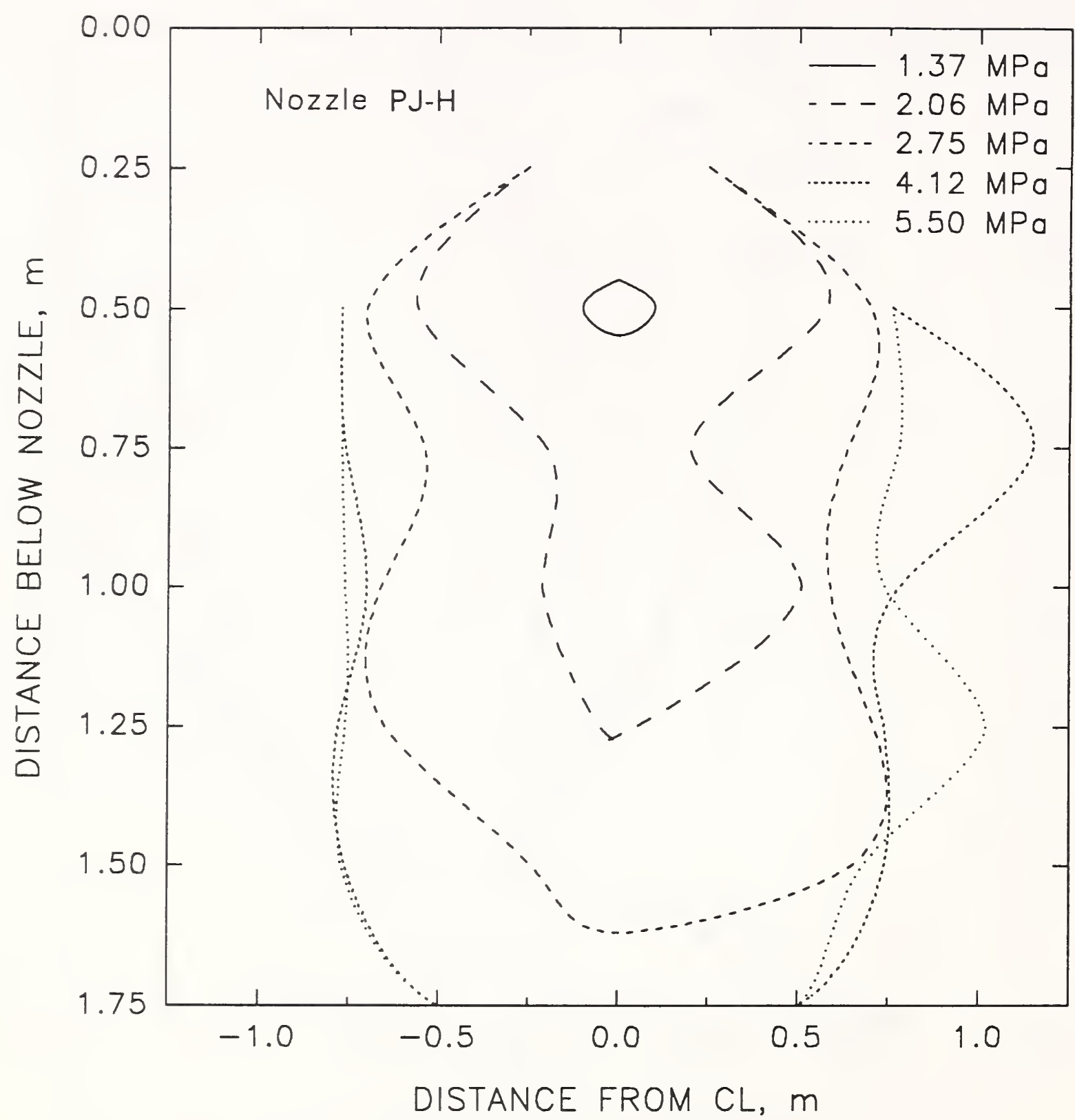

Figure 28. Contour plot showing regions where unobstructed test fires are extinguished in less than 60 s using a PJ-H pressure-jet nozzle. Pressure is the parameter. 


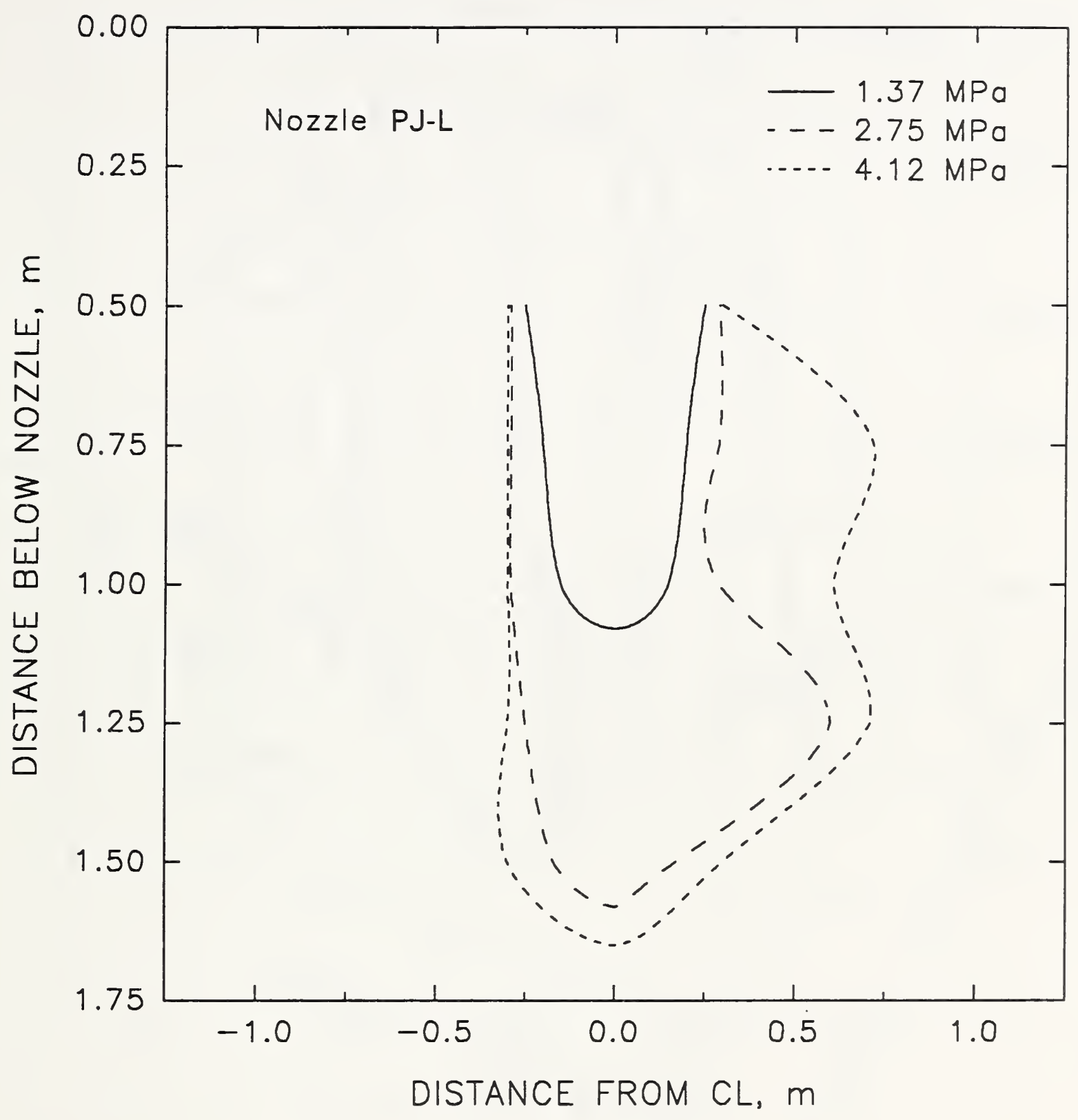

Figure 29. Contour plot showing regions where unobstructed test fires are extinguished in less than $60 \mathrm{~s}$ using a PJ-L pressure-jet nozzle. Pressure is the parameter. 


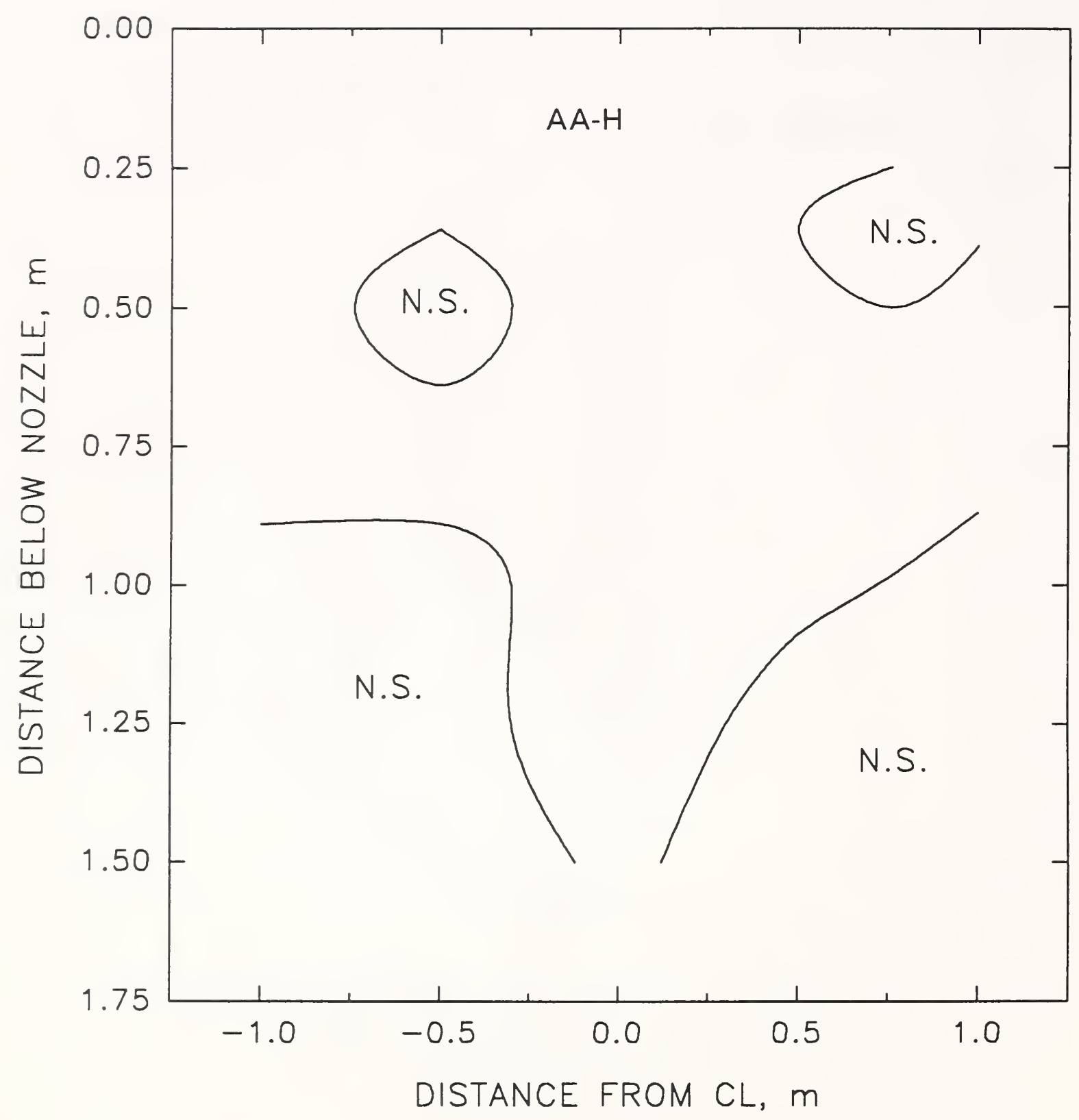

Figure 30. Contour plot showing regions where unobstructed test fires are extinguished using an AA-H air-atomized nozzle at recommended air and water pressures. N.S. implies no suppression within $60 \mathrm{~s}$. 


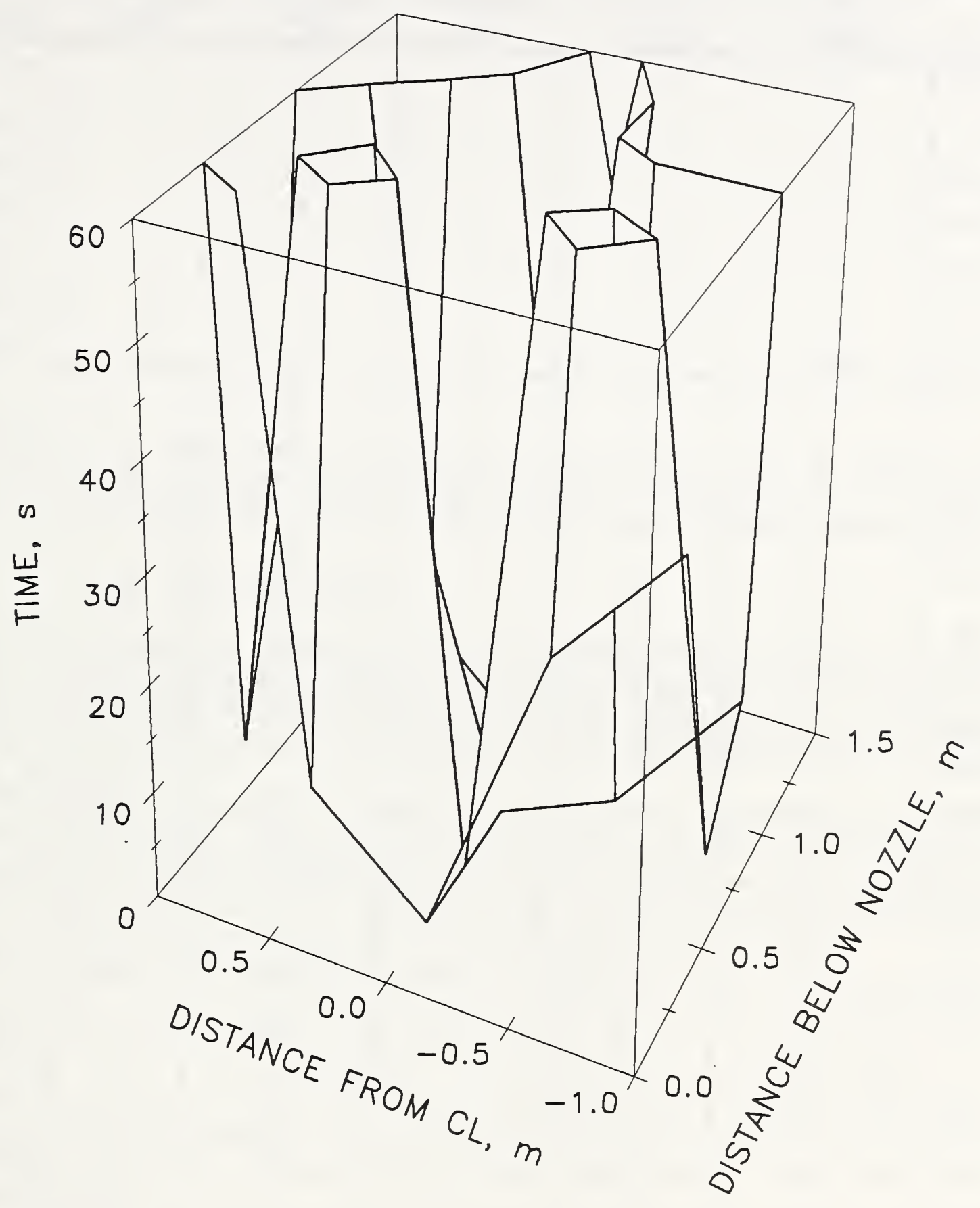

Figure 31. Time to extinction of unobstructed test fires for AA-H air-atomized nozzle, as a function of distance from nozzle exit. 
Table 3a. Test matrix for suppression of mock computer cabinet fire using a pressure-jet nozzle (PJ-H)

\begin{tabular}{|c|c|c|c|c|c|c|}
\hline Config \# & $\begin{array}{c}\text { Nozzle Pressure, } \\
\mathrm{MPa} \\
\end{array}$ & $\begin{array}{c}\begin{array}{c}\text { Y-Location } \\
(\mathrm{m})\end{array} \\
\end{array}$ & $\begin{array}{c}\text { X-Location } \\
(\mathrm{m})\end{array}$ & $\begin{array}{c}\text { Plate Spacing } \\
(\mathrm{mm})\end{array}$ & $\begin{array}{c}\text { Top } \\
\text { Surface } \\
\end{array}$ & Fan \\
\hline $1 / w 5$ & 5.5 & 0 & 1 & 50 & $\mathrm{~s}$ & off \\
\hline $2 / w 5$ & 5.5 & 0 & 1 & 50 & $\mathrm{~s}$ & up \\
\hline $3 / w 5$ & 5.5 & 0 & 1 & 50 & $\mathrm{~s}$ & down \\
\hline $4 / w 5$ & 5.5 & 0 & 1 & 50 & $\mathrm{r}$ & off \\
\hline $5 / w 5$ & 5.5 & 0 & 1 & 50 & $\mathrm{r}$ & up \\
\hline $6 / w 5$ & 5.5 & 0 & 1 & 50 & $r$ & down \\
\hline $7 / w 5$ & 5.5 & 0 & 1 & 25 & $\mathrm{~s}$ & off \\
\hline $8 / w 5$ & 5.5 & 0 & 1 & 25 & $\mathrm{~s}$ & up \\
\hline $9 / w 5$ & 5.5 & 0 & 1 & 25 & $\mathrm{~s}$ & down \\
\hline $10 / w 5$ & 5.5 & 0 & 1 & 25 & $r$ & off \\
\hline $11 / w 5$ & 5.5 & 0 & 1 & 25 & r & up \\
\hline $12 / w 5$ & 5.5 & 0 & 1 & 25 & $r$ & down \\
\hline $13 / w 5$ & 5.5 & 0 & .5 & 50 & $\mathrm{r}$ & off \\
\hline $14 / w 5$ & 5.5 & 0 & .5 & 50 & $s$ & off \\
\hline $15 / w 5$ & 5.5 & 0 & .5 & 25 & $r$ & off \\
\hline $16 / w 5$ & 5.5 & 0 & .5 & 25 & s & off \\
\hline $17 / w 5$ & 5.5 & .5 & 1 & 50 & $s$ & off \\
\hline $18 / w 5$ & 5.5 & .5 & 1 & 50 & $r$ & off \\
\hline $19 / w 5$ & 5.5 & .5 & 1 & 25 & s & off \\
\hline $20 / w 5$ & 5.5 & .5 & 1 & 25 & r & off \\
\hline $21 / w 5$ & 5.5 & 0 & 1.5 & 50 & $\mathrm{~s}$ & off \\
\hline $22 / w 2$ & 2.1 & 0 & 1 & 50 & s & off \\
\hline 23/w2 & 2.1 & 0 & 1 & 50 & s & down \\
\hline $24 /$ w2 & 2.1 & 0 & 1 & 50 & r & off \\
\hline $25 / w 2$ & 2.1 & 0 & 1 & 50 & r & down \\
\hline $26 / w 2$ & 2.1 & 0 & 1 & 25 & $s$ & off \\
\hline $27 /$ w2 & 2.1 & 0 & 1 & 25 & $\mathrm{~s}$ & down \\
\hline 28/w2 & 2.1 & 0 & 1 & 25 & $r$ & off \\
\hline $29 / w 2$ & 2.1 & 0 & 1 & 25 & $\mathrm{r}$ & down \\
\hline $30 / w 2$ & 2.1 & 0 & .5 & 50 & s & off \\
\hline $31 / w 2$ & 2.1 & .5 & 1 & 50 & $\mathrm{~s}$ & off \\
\hline
\end{tabular}


Table 3b. Test matrix for suppression of mock computer cabinet fire using gaseous $\mathrm{CF}_{3} \mathrm{H}$

\begin{tabular}{||c|c|c|c|c|c|c||}
\hline Config \# & $\begin{array}{c}\text { Nozzle Pressure, } \\
\text { MPa }\end{array}$ & $\begin{array}{c}\text { Y-Location } \\
(\mathrm{m})\end{array}$ & $\begin{array}{c}\text { X-Location } \\
(\mathrm{m})\end{array}$ & $\begin{array}{c}\text { Plate Spacing } \\
(\mathrm{mm})\end{array}$ & $\begin{array}{c}\text { Top } \\
\text { Surface }\end{array}$ & Fan \\
\hline \hline $32 / \mathrm{g} 4$ & 4.0 & 0 & 1 & 25 & $\mathrm{r}$ & off \\
$33 / \mathrm{g} 4$ & 4.0 & 0 & 1 & 25 & $\mathrm{r}$ & up \\
$34 / \mathrm{g} 4$ & 4.0 & 0 & 1 & 25 & $\mathrm{r}$ & down \\
$35 / \mathrm{g} 4$ & 4.0 & .5 & 1 & 25 & $\mathrm{r}$ & off \\
$36 / \mathrm{g} 4$ & 4.0 & 0 & .5 & 25 & $\mathrm{r}$ & off \\
$37 / \mathrm{g} 4$ & 4.0 & 0 & 1.5 & 25 & $\mathrm{r}$ & off \\
$38 / \mathrm{g} 4$ & 4.0 & 0 & 1 & 25 & closed & up \\
\hline
\end{tabular}

plate spacing is the distance between adjacent mock circuit boards. The top surface condition is designated "s" for the square, $80 \%$ open area pattern; " $r$ " for the round holes with $40 \%$ open area; and "closed" is for a solid top surface. The fans were either off, blowing upward, or blowing downward.

\subsubsection{Water Spray Results}

Of the 93 water suppression tests, 65 were unsuccessful in putting out the PMMA fire in the mock computer cabinet in less than $60 \mathrm{~s}$. The test conditions which extinguished the fire are shown in Table 4. In all cases except one the fire was extinguished for each of three replicates. For configuration \# $15 / \mathrm{w} 5$, the fire was suppressed in $55 \mathrm{~s}$ in the first test, and was not suppressed within $60 \mathrm{~s}$ in the second and third repeat runs.

The parameters which had the most dramatic effect on the suppression process were the Ylocation, the nozzle pressure, and the geometry of the top surface. The fires could be extinguished only on centerline $(Y=0 \mathrm{~m})$, for the highest nozzle pressure $(\mathrm{P}=5.5 \mathrm{MPa})$, and for the maximum open top surface area ( $80 \%$ open squares). The exception was one case with the $40 \%$ open area top surface, on centerline and with maximum pressure, and closest to the nozzle exit $(\mathrm{X}=0.5 \mathrm{~m})$.

The parameters which had very little impact on the suppression time were the plate spacing and the fan operation. As the test article was moved from 0.5 to 1.0 to $1.5 \mathrm{~m}$ downstream (on centerline, maximum pressure, $80 \%$ open area, $50 \mathrm{~mm}$ spacing, fan off), the time to suppress the fire increased, on average, from 1 to 10 to $23 \mathrm{~s}$, respectively. The $25 \mathrm{~mm}$ parallel plate spacing lead to an average suppression time about twice that for the $50 \mathrm{~mm}$ plate spacing, all other conditions being equal. There was a slight trend towards increasing time for suppression as the fans changed from the off condition to the up condition and then to a downward flow, but the limited number of data make it difficult to generalize this result.

Configuration \#1/w5 was chosen as representative of a successful suppression configuration for which droplet velocity and size distribution information were collected. The effect of the article on the spray in the absence of a fire was determined by placing the mock computer cabinet into the enclosure and measuring the spray parameters on the centerline, 0.60 and $0.82 \mathrm{~m}$ below the nozzle exit. These are compared in the Table 5 to the PDPA measurements described in section 3.2.1, for which the test article was not present.

An X-location of $0.60 \mathrm{~m}$ is $0.18 \mathrm{~m}$ above the top surface of the test article. The average vertical 
Table 4. Conditions for successful suppression of mock computer cabinet fire using PJ-H nozzle

\begin{tabular}{||c|c|c|c|c|c|c||}
\hline Config \# & $\begin{array}{c}\text { Y-Location } \\
(\mathrm{m})\end{array}$ & $\begin{array}{c}\text { X-Location } \\
(\mathrm{m})\end{array}$ & $\begin{array}{c}\text { Plate Spacing } \\
(\mathrm{mm})\end{array}$ & $\begin{array}{c}\text { Top } \\
\text { Surface }\end{array}$ & Fan & $\begin{array}{c}\text { Suppression } \\
\text { Time, } \mathrm{s}\end{array}$ \\
\hline \hline $1 / w 5$ & 0 & 1 & 50 & $\mathrm{~s}$ & off & 6 to 16 \\
$2 / w 5$ & 0 & 1 & 50 & $\mathrm{~s}$ & up & 6 to 9 \\
$3 / w 5$ & 0 & 1 & 50 & $\mathrm{~s}$ & down & 9 to 10 \\
$7 / w 5$ & 0 & 1 & 25 & $\mathrm{~s}$ & off & 0 \\
$8 / w 5$ & 0 & 1 & 25 & $\mathrm{~s}$ & up & 0 to 40 \\
$9 / w 5$ & 0 & 1 & 25 & $\mathrm{~s}$ & down & 30 to 40 \\
$14 / w 5$ & 0 & .5 & 50 & $\mathrm{~s}$ & off & 0 to 5 \\
$15 / w 5$ & 0 & .5 & 25 & $\mathrm{r}$ & off & $>55$ \\
$16 / w 5$ & 0 & .5 & 25 & $\mathrm{~s}$ & off & 0 \\
$21 / w 5$ & 0 & 1.5 & 50 & $\mathrm{~s}$ & off & 20 to 30 \\
\hline
\end{tabular}

Table 5. Comparison of spray characteristics with and without test article in place. Configuration is $\# 1 /$ w5 and PDPA measuring location is on centerline.

\begin{tabular}{|c|c|c|c|c|c|c|c|c|c|c|}
\hline \multirow{2}{*}{$\begin{array}{c}\text { Test } \\
\text { Condition }\end{array}$} & \multirow{2}{*}{$\begin{array}{c}\mathrm{X} \\
\text { location } \\
\mathrm{m}\end{array}$} & \multirow{2}{*}{$\begin{array}{l}\text { Average } \\
\text { Nozzle } \\
\text { Pressur } \\
\text { e MPag }\end{array}$} & \multirow{2}{*}{$\begin{array}{l}\text { Average } \\
\text { Water } \\
\text { Flow } \\
l / \text { min }\end{array}$} & \multicolumn{2}{|c|}{$\begin{array}{l}\text { Sauter Mean } \\
\text { Diameter, } \mu \mathrm{m}\end{array}$} & \multicolumn{2}{|c|}{$\begin{array}{c}\text { Number Density } \\
\mathrm{m}^{-1} \text { (\# valid) }\end{array}$} & \multicolumn{2}{|c|}{$\begin{array}{c}\text { Vertical } \\
\text { Speed, m/s }\end{array}$} & \multirow{2}{*}{$\begin{array}{c}\text { Average } \\
\text { Horizontal } \\
\text { Speed, } \\
\mathrm{m} / \mathrm{s}\end{array}$} \\
\hline & & & & $\begin{array}{c}1 \mathrm{st} \\
30 \mathrm{~s}\end{array}$ & $\begin{array}{l}2 \mathrm{nd} \\
30 \mathrm{~s}\end{array}$ & $\begin{array}{c}1 \mathrm{st} \\
30 \mathrm{~s}\end{array}$ & $\begin{array}{l}2 \mathrm{nd} \\
30 \mathrm{~s}\end{array}$ & $\begin{array}{c}1 \mathrm{st} \\
30 \mathrm{~s}\end{array}$ & $\begin{array}{l}2 \mathrm{nd} \\
30 \mathrm{~s}\end{array}$ & \\
\hline No article & 0.60 & 5.40 & 3.78 & 38 & 48 & $\begin{array}{c}78 \\
(2600)\end{array}$ & $\begin{array}{c}43 \\
(2700)\end{array}$ & 15.9 & 14.0 & -1.2 \\
\hline Test article & 0.60 & 5.49 & 3.82 & 38 & 44 & $\begin{array}{c}18 \\
(1600)\end{array}$ & $\begin{array}{c}12 \\
(1000)\end{array}$ & 16.0 & 15.7 & -1.0 \\
\hline No article & 0.82 & 5.49 & 3.77 & 60 & 61 & $\begin{array}{c}150 \\
(2500)\end{array}$ & $\begin{array}{c}242 \\
(2500)\end{array}$ & 12.6 & 12.0 & -0.3 \\
\hline $\begin{array}{l}30 \mathrm{~mm} \\
\text { above test } \\
\text { article (s) }\end{array}$ & 0.82 & 5.47 & 3.77 & 53 & 62 & $\begin{array}{c}92 \\
(2300)\end{array}$ & $\begin{array}{c}72 \\
(2800)\end{array}$ & 12.8 & 13.0 & -0.4 \\
\hline $\begin{array}{l}30 \mathrm{~mm} \\
\text { above test } \\
\text { article }(\mathrm{r})\end{array}$ & 0.82 & 5.45 & 3.75 & 51 & 45 & $\begin{array}{c}29 \\
(500)\end{array}$ & $\begin{array}{c}31 \\
(300)\end{array}$ & 13.0 & 12.5 & -0.1 \\
\hline $\begin{array}{c}30 \mathrm{~mm} \\
\text { below } 80 \% \\
\text { open screen }\end{array}$ & 0.82 & 5.44 & 3.77 & 52 & 58 & $\begin{array}{c}194 \\
(2600)\end{array}$ & $\begin{array}{c}225 \\
(2900)\end{array}$ & 11.4 & 10.3 & -0.1 \\
\hline $\begin{array}{c}30 \mathrm{~mm} \\
\text { below } 40 \% \\
\text { open screen }\end{array}$ & 0.82 & 5.45 & 3.73 & 66 & 65 & $\begin{array}{c}68 \\
(700)\end{array}$ & $\begin{array}{c}17 \\
(200)\end{array}$ & 4.4 & 5.3 & +0.6 \\
\hline
\end{tabular}


velocity increases $0.9 \mathrm{~m} / \mathrm{s}$ when the mock computer cabinet is present, which is less than the uncertainty in the measurement found through repeating the test under the same conditions. The number density drops by a factor of four with the installation of the test article. It is unclear if this is a real effect or due to changes in the condition of the PDPA, such as increased condensation on the optics created by the different flow patterns, but there is also a significant drop in the number of valid samples detected by the PDPA.

The SMD 30 on the centerline $0.82 \mathrm{~m}$ below the nozzle exit was about $60 \mu \mathrm{m}$ when the spray chamber was empty, and the average vertical speed was a little over $12 \mathrm{~m} / \mathrm{s}$. Inserting the test article 30 $\mathrm{mm}$ below the PDPA measuring point had little effect on the SMD and increased the vertical velocity about $0.7 \mathrm{~m} / \mathrm{s}$. The number density just above the article was cut about in half although there was no significant change in the number of valid samples (about 2500 during the $60 \mathrm{~s}$ sampling period). For a sample to be valid the particle must pass through the central portion of the probe volume. Optical access to the underside of the top surface of the computer cabinet was designed, but the rapid build-up of droplets on the windows did not permit a long enough sampling time for the PDPA to yield meaningful results. To get around this problem the top was suspended in place with a fixture and the remainder of the computer cabinet was removed. The PDPA was focused $30 \mathrm{~mm}$ below the top screen and the tests were repeated. The $80 \%$ open-area screen had a modest impact on the droplet behavior. Referring to Table 5, one can see that the average vertical speed decreased from $13.0 \mathrm{~m} / \mathrm{s}$ just above the test article to $10.6 \mathrm{~m} / \mathrm{s}$ below the $80 \%$ open-area screen. The SMD and horizontal component of velocity were unaffected by the screen; however, the number density more than doubled with no change in the number of valid samples. Decreasing the open area to $40 \%$ had a more profound effect. The SMD increased from 48 to $65 \mu \mathrm{m}$ and the horizontal velocity component became slightly positive. The average vertical speed dropped from $13 \mathrm{~m} / \mathrm{s}$ above the test article with the same top surface ( $\mathrm{r}$ ) to less than $5 \mathrm{~m} / \mathrm{s}$ below the screen. The number of droplets per unit volume and the number of valid samples were small above and below the $40 \%$ open-area screen due to a combination of the interaction of the drops with the solid portion of the top surface and the greatly enhanced splashing that quickly degraded the optics of the PDPA.

With some feeling for the impact of the mock computer cabinet on the PJ-H spray in the absence of a fire, a series of experiments to measure the spray parameters in a burning situation were conducted using test configurations \#1/w5 and \#2/w5. The sampling point for the PDPA remained the same, 30 $\mathrm{mm}$ above the top surface. The results are compared to the equivalent cold flow test below:

$\begin{array}{lll}\text { Parameter } & \text { Cold Flow } & \text { Fire } \\ \text { nozzle pressure } & 5.47 \mathrm{MPag} & 5.40 \mathrm{MPag} \\ \text { water flow } & 3.77 \mathrm{l} / \mathrm{min} & 3.77 \mathrm{l} / \mathrm{min} \\ \text { SMD } & 58 \mu \mathrm{m} & 56 \mu \mathrm{m} \\ \text { vertical speed } & 13.0 \mathrm{~m} / \mathrm{s} & 11.3 \mathrm{~m} / \mathrm{s} \\ \text { number density } & 82 / \mathrm{ml} & 120 / \mathrm{ml}\end{array}$

The fire did not modify the SMD. The buoyant plume created by the fire may have accounted for some of the $1.7 \mathrm{~m} / \mathrm{s}$ decrease in vertical droplet speed. The time needed to suppress the four test fires in which the droplet parameters were measured varied from under $5 \mathrm{~s}$ for two to around $45 \mathrm{~s}$ for two others. This compares to a range of 6 to $16 \mathrm{~s}$ for the initial fire suppression tests listed in Table 4 .

Two additional replicates of configuration $\# 2 /$ w5 were conducted. The presence of the upward blowing fans had no noticeable impact on the droplet velocity or size. For some reason, the time to suppression increased to $50 \mathrm{~s}$ for one replicate and exceeded $60 \mathrm{~s}$ for the other. This is much greater than the 6 to $9 \mathrm{~s}$ reported in Table 4. No obvious explanation for this discrepancy has been identified.

A couple of experiments were run with the upper surface totally removed. The fire went out in 
less than $5 \mathrm{~s}$ for each of these. The average vertical speed was about $12 \mathrm{~m} / \mathrm{s}$, slightly higher than with the top surface in place. This is probably due to the weaker turbulent plume which exists earlier in the fire. The results remained unchanged with the top surface open and the ventilating fans blowing upward.

\subsubsection{Suppression with gaseous $\mathrm{CF}_{3} \mathrm{H}$}

The amount of agent likely to be needed to suppress the fire was estimated from the cup burner results of Hamins et al. (1994), plus 20\%. This translates to a volume fraction of $14 \%$, as compared to only $4 \%$ for halon 1301 . Live-fire experiments were conducted using the mock computer cabinet geometry specified in Table $3 \mathrm{~b}$, configurations \#32/g4 to \#38/g4. The fire was initiated as in the water spray experiments, and the amount of agent was increased until suppression could be attained in less than $60 \mathrm{~s}$.

Of 24 discharges, all but seven extinguished the fire in less than $60 \mathrm{~s}$. The conditions leading to successful suppression were independent of the parameters listed in Table $3 \mathrm{~b}$. Only the ultimate concentration of the $\mathrm{CF}_{3} \mathrm{H}$ affected the results. The flames were always extinguished within $20 \mathrm{~s}$ when the average volume fraction of $\mathrm{CF}_{3} \mathrm{H}$ (based upon the total mass delivered and the chamber volume) was estimated to be greater than about $10 \%$, irrespective of where the mock computer cabinet was located and independent of the operation of the fans. The closed top surface configuration increased the time to suppression to over $60 \mathrm{~s}$, but these tests were all done at nominal concentrations less than $10 \%$.

Gaseous $\mathrm{CF}_{3} \mathrm{H}$ at standard conditions is nearly $60 \%$ more dense then the air within the enclosure. This fact may explain why the fires in the test article (which was located in the lower portion of the chamber) were suppressed at less than the design concentration (14\%). There are two other factors which contributed to the better than expected performance of $\mathrm{CF}_{3} \mathrm{H}$, as well: (1) the estimated concentrations do not account for the additional agent delivered during the transient operation of the solenoid valve (as much as $25 \%$ or more); and (2) the velocity of the incoming gas may approach sonic speeds, imparting a large amount of momentum to the air which can contribute to the destabilization of the flame.

A troubling sidelight of the release of gaseous $\mathrm{CF}_{3} \mathrm{H}$ was the appearance of a noticeable amount of hydrogen fluoride (HF) when the agent was pyrolyzed. The HF appeared as a hazy white smoke well above the test article. This smoke was circulated throughout the enclosure before depositing on the inner surfaces of the chamber. The glass walls of the enclosure were severely etched by the HF after only four tests. This is consistent with the observations of others, but it brought home the possibility of significant collateral damage from what is considered a "clean" agent.

The key point made with this series of experiments was that a gaseous alternative to halon 1301 was capable of extinguishing the fire under conditions that the fine water spray was found to be ineffective. 


\section{Conclusions and Recommendations}

\subsection{Conclusions Regarding Experimental Facility}

A new facility has been designed and built to study the interaction between a water spray and a small enclosure fire. It is capable of accurately monitoring water flow rates up to $10 \mathrm{l} / \mathrm{min}$ and water and gas pressures up to $6 \mathrm{MPag}$. Single and multiple pressure-jet and air-atomizing water nozzles can be accommodated. Gaseous alternatives to halon 1301, such as $\mathrm{CF}_{3} \mathrm{H}$, can be discharged into the approximately $3 \mathrm{~m}^{3}$ volume.

Water droplet velocities in the range of 0 to $30 \mathrm{~m} / \mathrm{s}$ and size distributions with mean diameters in the range of 4 to $150 \mu \mathrm{m}$ have been determined in situ using a phase-Doppler particle analyzer. The fiber-based transmitting and receiving optics can be protected for many applications against droplet deposition, but in other situations the splashing of water onto the lenses quickly degrades the performance of the instrument.

The ignition, early growth phase, and suppression of a PMMA, simulated circuit board fire can be conducted in a consistent manner, allowing an accurate assessment of alternative suppressant system designs. The fires investigated were limited to a few kilowatts heat release rate, but this could be safely increased by a factor of two or three.

\subsection{Conclusions Regarding Fire Suppression}

The research performed in this study was limited to a specific enclosure geometry and fire threat. Two different nozzle designs, each with a high and low flow rating, were examined. As many relevant parameters were varied as was possible to arrive at general conclusions regarding the suitability of an externally located fine water spray for extinguishing an in-cabinet fire. The ability of a fine water spray to effectively suppress a small fire that is obstructed from the discharge nozzle is most strongly dependent upon the following parameters:

- fraction of open area between the nozzle and the fire

- lateral distance between fire and the highest droplet concentration

- water pressure, or, more precisely, the spray momentum

The distance below the nozzle exit and between vertically-spaced circuit boards has a secondary effect on the time to suppression. The flow created by cabinet cooling fans was insufficient to impact the time required to extinguish the fire in one series of tests; however, in a second series, the upward flow appears to have significantly lengthened the time to suppression.

Measurements of axial droplet velocities indicate that, for a given location in the spray and all other conditions constant, a simple, thin porous plate decreases the spray velocity about in proportion to the area open to the flow. The associated decrease in jet momentum and total water flux greatly reduces the chances for successful fire suppression. The current study was unable to distinguish which of these effects dominates the extinction process. While some increase in droplet diameter was observed when the spray passed through the porous plate, no conclusions can be drawn regarding the importance of the droplet size to the suppression of circuit board fires.

From this study one can conclude that fine water spray suppression systems similar to those examined that have nozzles located external to computer cabinets are unlikely to be able to extinguish fires within the units anywhere near as effectively as a gaseous agent. This does not rule out the possibility that a water spray system could be designed to aid in the protection computer centers and data processing equipment, however. Ultra-fine droplet ( $<10 \mu \mathrm{m}$ diameter), low momentum sprays 
and systems using very high pressures ( $>10 \mathrm{MPa}$ ) were not evaluated in this study. Additional testing is necessary on these systems before passing final judgement.

\subsection{Recommendations}

The dynamics of fine water spray suppression are not well understood. Further research is required to identify the relative importance of droplet size, spray momentum and water flux on flame extinction. Experiments need to be designed to independently control each of these variables. Does the order of importance vary with the type of fuel, size of the fire, or orientation? Knowing which of these parameters dominates and under what conditions would allow improved systems to be developed and optimized for specific applications.

If external fine water sprays such as those examined are not effective against deep-seated fires within electronics cabinets, what alternatives are recommended? An in-cabinet, self-contained gaseous suppressant system is one technology that already exists. One could also envision a mechanical system which closes the inlets and exhausts to isolate the cabinet following a localized power cut-off, suffocating the fire and minimizing the transport of smoke aerosols. Such a system should be compared against a super-fine water spray $\left(D_{v}<10 \mu \mathrm{m}\right)$ that could be released near the cabinet air inlet or in the sub-floor area.

Further research into other aspects of the protection of computer rooms with fine water sprays is required to accelerate the acceptance of this technology. The main issue that needs to be laid to rest is the one of collateral damage. Research is recommended to quantify how the water droplets are transported into equipment not on fire but located in the same room. How do these droplets interact with the products of combustion (especially $\mathrm{HCl}, \mathrm{HF}$ and soot) to enhance their transport into adjacent equipment? Under what conditions is it possible to maintain power to computer equipment without fear of arcing?

Fine water spray fire suppression systems may not always be the optimum choice, but if we grow to understand how water sprays actually extinguish fires, the envelope of applications can be extended and the limitations of the technology will be established based upon physics and not merely speculation. 


\section{References}

Aerometrics Inc., Sunnyvale, CA, "Probe Volume Correction and Related Calculations," (In-house document), 1993a.

Aerometrics Inc., Sunnyvale, CA, "Phase Doppler Particle Analyzer/Doppler Signal Analyzer - 2 Component User's Manual, Release 1.0," pp. 10-47,48, January 1993 b.

Allianz Risk Service, "Fire and Extinguishment Tests on Computer Equipment," Fire Systems 5, no. 2 , 61-72, 1991.

Alpert, R.L., "Incentives for Use of Misting Sprays as a Fire Suppression Flooding Agent," in Water Mist Fire Suppression Workshop, March 1-2, 1993: Proceedings, Notarianni, K.A., and Jason, N. H., eds, NISTIR 5207, National Institute of Standards and Technology, Gaithersburg, MD, 1993.

Bachalo, W.D., "The Phase Doppler Method: Analysis and Application", Optical Particle Sizing, Plenum Publishing Corp., 1988

Bachalo, W.D., and M.J. Houser, "Phase/Doppler spray analyzer for simultaneous measurements of drop size and velocity distributions," Optical Engineering, Vol. 23, 583-590, Sept/Oct, 1984.

Bryant, P., "Fire protection in EDP areas - no easy answers," Fire Prevention 256, 18-19, Jan./Feb. 1993.

Environmental Protection Agency, "Significant New Alternative Policy Program," Federal Register, vol. 58, 90, pp. 28102-28104, May 12, 1993.

Hamins, A., Gmurczyk, G., Grosshandler, W., Rehwoldt, R., Vazquez, I., Cleary, T., Presser, C., and Seshadri, K., "Flame Suppression Effectiveness," Section 4 in Evaluation of Alternative In-flight Fire Suppressants for Full-scale Testing in Simulated Aircraft Engine Nacelles and Dry Bays, W. Grosshandler, R. Gann and W. Pitts, editors, NIST SP 861, April 1984.

Harrington, J.L., "The Halon Phaseout Speeds Up," NFPA Journal 87, no. 2., 38-42, 1993

Hills, A.T., Simpson, T., and Smith, D.P., "Water Mist Fire Protection Systems for Telecommunications Switch Gear and Other Electronic Facilities," in Water Mist Fire Suppression Workshop, March 1-2, 1993: Proceedings, Notarianni, K.A., and Jason, N. H., eds, NISTIR 5207, National Institute of Standards and Technology, June 1993.

Holman, J.P., Experimental Methods for Engineers, Fourth Edition, McGraw Hill Book Company, Pages 235-243, 1984.

Layman, Lloyd, "Fire Fighting Tactics," National Fire Protection Association, Boston, MA, 1953.

Mawhinney, J.R., "Design of Water Mist Fire Suppression Systems for Shipboard Enclosures," in Water Mist Instead of Halon? International Conference on Water Mist Fire Suppression Systems: Proceedings, 
Swedish National Testing and Research Institute, Boras, Sweden, November 4-5, 1993.

NFPA 15, "Water Spray Systems for Fire Protection," in National Fire Codes Vol IV, National Fire Protection Association, 1947.

NFPA 2001, "Clean Agent Fire Extinguishing Systems," National Fire Protection Association, in review, 1994.

National Fire Protection Association, "Studies of Fire Department 'Fog' or Water Spray Nozzles," Boston, MA, 1952.

Notarianni, K.A., and N.H. Jason, eds, Water Mist Fire Suppression Workshop, March 1-2, 1993: Proceedings, NISTIR 5207, National Institute of Standards and Technology, Gaithersburg, MD, 1993.

Pepi, J.S., "Water Mist: A Technology Overview and Status Report on the AquaMist ${ }^{\mathrm{TM}}$ System for Marine Cabins, Corridors, and Public Spaces", Grinnell Corporation, May, 1994.

"Post-Halon Computer Protection," Record 70, no. 5, 3-9, Nov./Dec., 1993.

Price, B.J., "Computer Room Fire Protection," Library Hi Tech 29, no. 1, 43-56, 1990.

Rudoff, R.C., S.V. Sankar, W.D. Bachalo, PSA 1991 Conference, "Using the Phase Doppler Particle Analyzer for In-Situ Sizing of Fine Spherical Particles," September 17, 1991.

Simmons, F., "Computer room protection - the debate continues," Fire Prevention 232, pp. ?, Sept. 1990.

Taylor, K.T., "Updating the Record on Computer Center Fires," Fire Journal 83, no.2, 31-35, Mar./Apr. 1989.

Underwriters' Laboratories, Inc., "The Mechanism of Extinguishment of Fire by Finely Divided Water," conducted for The National Board of Fire Underwriters, New York, N.Y., 1955. 

